THE GLOBAL DOWNTURN

\title{
AND ITS IMPACT
}

ON EURO AREA

\section{EXPORTS AND}

\section{COMPETITIVENESS}

by Filippo di Mauro, Katrin Forster and Ana Lima 


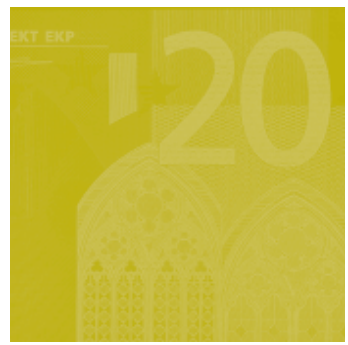

\section{OCCASIONAL PAPER SERIES}

NO II 9 / OCTOBER 2010

THE GLOBAL DOWNTURN

AND ITS IMPACT

ON EURO AREA EXPORTS AND COMPETITIVENESS '

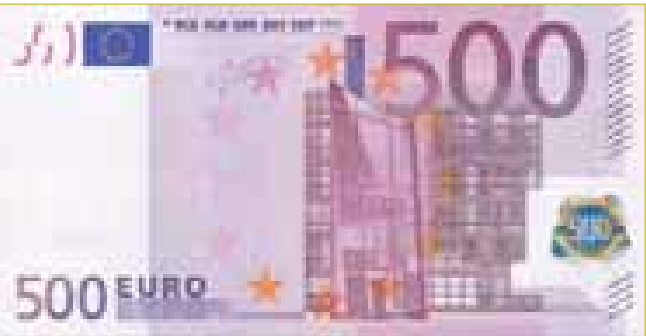

In 2010 all ECB

publications

feature a motif

$€ 500$ banknote. by Filippo di Mauro, Katrin Forster

and Ana Lima ${ }^{2}$

NOTE: This Occasional Paper should not be reported as representing the views of the European Central Bank (ECB).

The views expressed are those of the authors and do not necessarily reflect those of the $E C B$.

This paper can be downloaded without charge from http://www.ecb.europa.eu or from the Social Science Research Network electronic library at http://ssrn.com/abstract_id=1683325. 
(c) European Central Bank, 2010

\section{Address}

Kaiserstrasse 29

60311 Frankfurt am Main, Germany

Postal address

Postfach 160319

60066 Frankfurt am Main, Germany

Telephone

+496913440

Internet

http://www.ecb.europa.eu

Fax

+496913446000

All rights reserved.

Any reproduction, publication and reprint in the form of a different publication, whether printed or produced electronically, in whole or in part, is permitted only with the explicit written authorisation of the ECB or the authors.

Information on all of the papers published in the ECB Occasional Paper Series can be found on the ECB's website. http://www.ecb.europa.eu/pub/scientific/ ops/date/html/index.en.html

ISSN 1607-1484 (print)

ISSN 1725-6534 (online) 


\section{CONTENTS}

ABSTRACT

NON-TECHNICAL SUMMARY

I INTRODUCTION

2 THE RECENT COLLAPSE IN WORLD AND EURO AREA TRADE

2.1 Stylised facts about the recent collapse in trade

2.2 Main factors behind the downturn in trade: what has made this cycle so exceptional?

3 THE EURO AREA'S EXPORT

PERFORMANCE AND COMPETITIVENESS:

PRE-CRISIS TRENDS AND THE IMPACT

OF THE FINANCIAL CRISIS

3.1 Measuring competitiveness: some basic building blocks

3.2 Pre-crisis trends in euro area exports and competitiveness

3.3 Impact of the crisis on euro area competitiveness

4 PROSPECTS FOR EURO AREA TRADE AND COMPETITIVENESS: WHAT HAVE WE LEARNED FROM THE RECOVERY SO FAR?

4.1 The recent recovery in world trade and euro area exports

4.2 What does this imply for the euro area: main challenges and policy options going forward

1 Price competitiveness and euro area countries - additional information

2 Export specialisation by euro area country and by sector and data classifications
3 Overview on the method used to quantify overall and producer competitiveness

4 Determinants of trade performance in the new multi-country model

EUROPEAN CENTRAL BANK OCCASIONAL PAPER SERIES SINCE 2009 


\section{ABSTRACT}

World trade contracted sharply in late 2008 and early 2009 following the deepening of the financial crisis in September 2008. This paper discusses the main mechanisms behind the global downturn in trade and its impact on euro area exports and competitiveness. It finds that the euro area was hit particularly hard by the contraction in global demand. Moreover, the collapse in the demand for euro area products during the downturn was exacerbated to some degree by unfavourable developments in price competitiveness, resulting in further losses in competitiveness compared to our main trading partners, in line with pre-crisis trends. This view is also confirmed by evidence from broad-based competitiveness measures, which show that euro area countries recorded losses in productivity during this period. Going forward, the recovery in world trade will depend mainly on a resurgence in global demand and its expenditure composition. With regard to the euro area, as the global economy recovers at varying speeds and given the current growth momentum in emerging economies, the performance of the external sector may be hindered by the geographical orientation of its export markets, which are mainly focused on advanced economies and other EU member states. Furthermore, the strength and sustainability of the recovery in exports will also depend on the restructuring process undertaken by European firms in response to globalisation-related challenges. Governments within the European Union should therefore focus on policies to strengthen competition and increase market integration, in order to benefit fully from the globalisation process going forward. In contrast, a resurgence in global protectionist policies could dampen the prospects for world and euro area trade and should be strongly resisted.

Keywords: Trade, euro area, competitiveness.

J.E.L. classifications: F10, F15, F43. 


\section{NON-TECHNICAL SUMMARY}

After the deepening of the financial crisis, world trade contracted very sharply and rapidly in the final quarter of 2008 and first quarter of 2009 at a pace unprecedented in post-war history, causing world trade volumes to fall abruptly to 2005 levels. In line with the developments in world trade, the impact on euro area exports was also severe. This has led to concerns about the performance of the euro area's external sector and also raised the question as to what extent the crisis may have aggravated previous competitiveness issues. Against this background, the paper provides an initial assessment of the competitiveness of the euro area during and following the financial crisis, pointing to a number of challenges that need to be addressed timely.

First, by presenting assorted stylised facts about the global downturn in trade and the impact on euro area exports, the paper shows that the sharp contraction in global manufacturing output was the main reason behind the collapse in trade. Beyond this, a number of factors may have contributed to the exceptionally severe trade response to the decline in final demand. In particular, the composition of the demand shock seems to have played a key role. As the decline in GDP focused mostly on trade-intensive expenditure components (such as investment, exports and inventories) and durable goods, the fall in world trade was much bigger than what might have been expected from a simple model linking trade to final demand. Structural changes related to globalisation, such as the increasing role of international supply chains, may have acted as an additional amplification mechanism in this respect, which is also consistent with the large fall in trade in intermediate goods. Finally, tight credit conditions and their impact on trade finance may have exacerbated the short-term trade response.

The euro area's overall export market shares declined more than those of its main advanced competitors, with the exception of Japan.
Partly owing to the relatively high openness of the euro area and the export specialisation of some euro area countries, particularly in the hardest hit intermediate goods and capital goods sectors, the relatively weak competitive position constituted an additional factor. Some euro area countries have been more prone to the global downturn in trade and deteriorating financial conditions due to the accumulation of losses in price competitiveness and structural weaknesses, as reflected in relatively low productivity growth, together with fragilities in the banking system. As the recent European sovereign debt crisis has also shown, the unavoidable changes necessary for restoring competitiveness and strengthening productivity growth need to be implemented urgently.

Looking ahead, the prospects for a substantial recovery in the euro area's export performance depend mainly on its response to the existing challenges in a post-crisis world. In particular, it will depend on the implementation of ambitious competitiveness-enhancing policies. However, a number of factors may be playing unfavourably. First, with the world economy recovering at varying speeds and given the euro area's fairly strong dependence on demand from advanced economies and other EU member states - countries among the hardest hit by the crisis and so far the slowest to recover the euro area may not be able to benefit fully from the strong demand growth witnessed in the most dynamic emerging market economies (which account for a relatively modest share of total euro area exports). This relates to distance as well as to the export specialisation of the euro area, whereby raw materials, which were in high demand from emerging economies particularly during the initial recovery stages, play only a limited role. Second, the euro area may be particularly prone to the impact of any further spread in trade protectionism - in the form of explicit trade barriers or more subtle financial constraints and/or domestically targeted industrial policies. As the paper shows, since such policies would tend to dampen world trade growth and severely affect the most competitive member countries, the overall impact on the 
euro area will actually be rather pervasive. EU governments should focus on implementing policies that are designed more to raise market flexibility and enhance the competitive climate within the Union. This would make it easier for euro area firms to access foreign markets, enlarge domestic markets and increase the technological advancement of domestic firms and the quality of the institutional framework. 
I

\section{INTRODUCTION}

A striking feature of the recent financial and economic crisis was the collapse in world trade. International trade flows contracted sharply in the fourth quarter of 2008 and first quarter of 2009 following the deepening of the financial crisis in September 2008 and the associated downturn in global activity. The decline was unprecedented historically in terms of both its speed and magnitude and its high degree of synchronisation across countries. It was also exceptional in terms of its proportion to the decline in overall activity.

Being a relatively open economy, declining foreign demand in the wake of the 2008/09 global economic downturn hit the euro area's export sector particularly hard. This led to increasing concerns about the prospects for euro area exports and competitiveness, ${ }^{1}$ particularly at a time when euro area exporters had already been struggling to adjust to the fiercer competition and other structural changes resulting from globalisation. While the increasing integration of emerging economies into the world economy has provided new opportunities for advanced economies - opening up new and fast-growing markets for their products as well as providing opportunities to expand international production chains - those same developments have also brought about significant challenges to the competitiveness of the euro area, forcing euro area firms to undergo substantial restructuring in order to enhance their competitiveness.

Against this background, the main purpose of this Occasional Paper is to assess the impact of the global downturn on euro area exports and competitiveness. In particular, the paper assesses the extent to which the global downturn may have aggravated previously existing needs for readjustment and undermined the future prospects for euro area exports and competitiveness. The recent European sovereign debt crisis has made it even more apparent that further policy actions to restore competitiveness and strengthen productivity growth are unavoidable and necessary.

In more detail, this paper look at the unprecedented decline in global and euro area trade and reviews the main mechanisms behind the downturn. In particular, it aims to evaluate whether the factors behind the recent downturn have been a mere cyclical development, albeit a highly exceptional one, or whether the crisis is likely to have produced more of a structural change with longer-lasting repercussions. In terms of the prospects for euro area competitiveness, the starting point will be an examination of a broad set of fairly traditional indicators, such as export market share and price competitiveness. In line with earlier work (di Mauro and Forster, 2008) we will also complement this analysis with a more holistic set of indicators derived from a more complex, firm-level based framework aimed at capturing various aspects of price and non-price competitiveness.

The structure of the paper is as follows: Chapter 2 presents assorted stylised facts regarding the recent collapse in trade and the main factors behind this unprecedented decline. This chapter is designed to create the background for the discussion of competitiveness issues. Chapter 3 looks in more detail at issues related to the external competitiveness of the euro area and its member countries. Using a broad range of indicators, this chapter analyses the impacts of the crisis compared to previous trends. Chapter 4 explores the impact of the downturn on the outlook for the euro area's export performance and competitiveness. Chapter 5 concludes. The Occasional Paper also includes four technical annexes.

1 As a starting point, and in line with other major institutions (e.g. the OECD), we define competitiveness as "all those factors that impact on the ability of an economy to compete in international markets". This is a somewhat loose, but also comprehensive definition of competitiveness that will be discussed further in Chapter 3. 


\section{THE RECENT COLLAPSE IN WORLD AND EURO AREA TRADE}

With the intensification of the financial crisis in late 2008, global trade volumes suddenly contracted sharply, putting an end to a prolonged period of rapid growth. In line with these developments, euro area exports also collapsed. This chapter presents some stylised facts related to this period and analyses the main factors underlying the downturn in trade. This will provide the background for the ensuing discussion of developments with regard to euro area competitiveness and the outlook for euro area exports.

\section{I STYLISED FACTS ABOUT THE RECENT COLLAPSE IN TRADE}

\section{DEVELOPMENTS IN WORLD TRADE}

The global downturn in trade that followed the deepening of the financial crisis in late 2008 was exceptional in many respects. First of all, it came as a rapid, sharp shock, at an unparalleled pace unprecedented in post-war history (see Chart 1). ${ }^{2}$ Between September 2008 and March 2009 world merchandise trade fell by

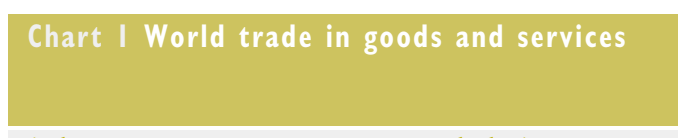

(volumes; year-on-year percentages; quarterly data)

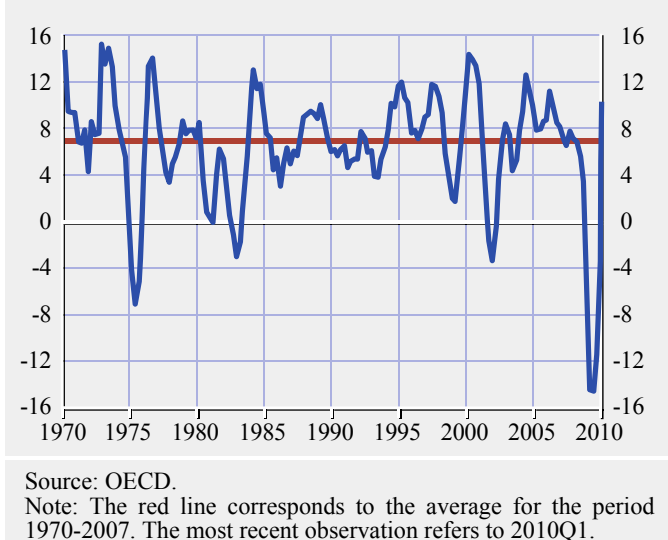

about $16 \%$ in real terms, bringing trade volumes down to near-2005 levels. In nominal terms, the fall in trade flows was even more pronounced, with trade values declining by around $23 \%$ over the same period on the back of sharp declines in commodity prices.

The downturn in trade was also exceptional in terms of the globally synchronised nature of the decline. After a relative strong performance in the first quarter of 2008, a large number of countries experienced a dramatic and synchronised decline in export volumes (see Chart 2). At the beginning of 2009 , approximately $90 \%$ of the countries reported declines in exports of more than $5 \%$, while about $30 \%$ of the countries recorded export falls in excess of $20 \%$. This degree of synchronisation is unparalleled in recent history. Although the decline was not as severe as during the Great Depression, it was certainly more synchronised and steeper: back then it took about 24 months for trade to fall

2 According to Eichengreen and O'Rourke (2009), trade volumes fell at a faster pace than during the first year of the Great Depression.

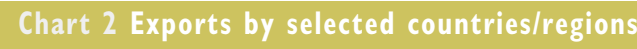

(goods volume indices: September 2008=100; 3-month moving (goods volume indices:

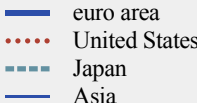

Asia

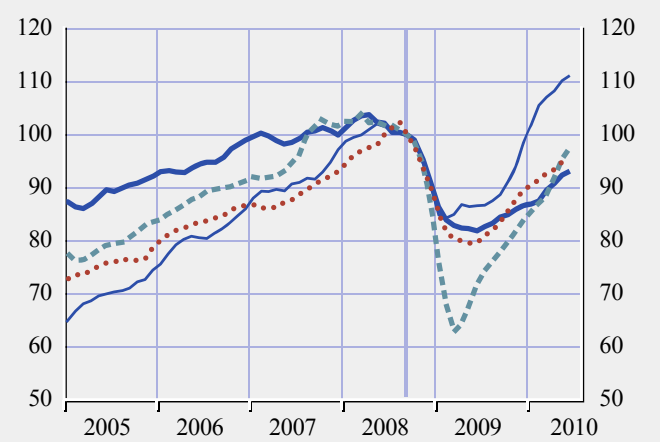

Source: Netherlands Bureau for Economic Policy Analysis (CPB) Notes: Euro area exports correspond to both intra- and extra-eur area exports. The most recent observation refers to June 2010 . 
to levels similar to those reached in just nine months during the recent downturn in trade (Eichengreen and Rourke, 2009 and Baldwin et al, 2009).

Another prominent feature of the global downturn in trade was the remarkably severe contraction in trade relative to the overall decline in domestic activity. In other words, the collapse in global trade flows significantly outstripped that of global GDP (see Chart 3), lowering the trade-to-GDP ratio by about 15 percentage points. Although trade historically tends to be more volatile than economic activity, particularly in global downturns, the apparent sensitivity of trade to changes in income during the recent trade slump significantly exceeded historical norms of estimated income elasticities. The overall decline in global activity during the winter of 2008/09 had a dramatic impact on trade volumes, which fell by more than five times the drop in output levels over the same period. ${ }^{3}$ Not surprisingly, standard export equations failed to fully explain this downturn in global trade. ${ }^{4}$

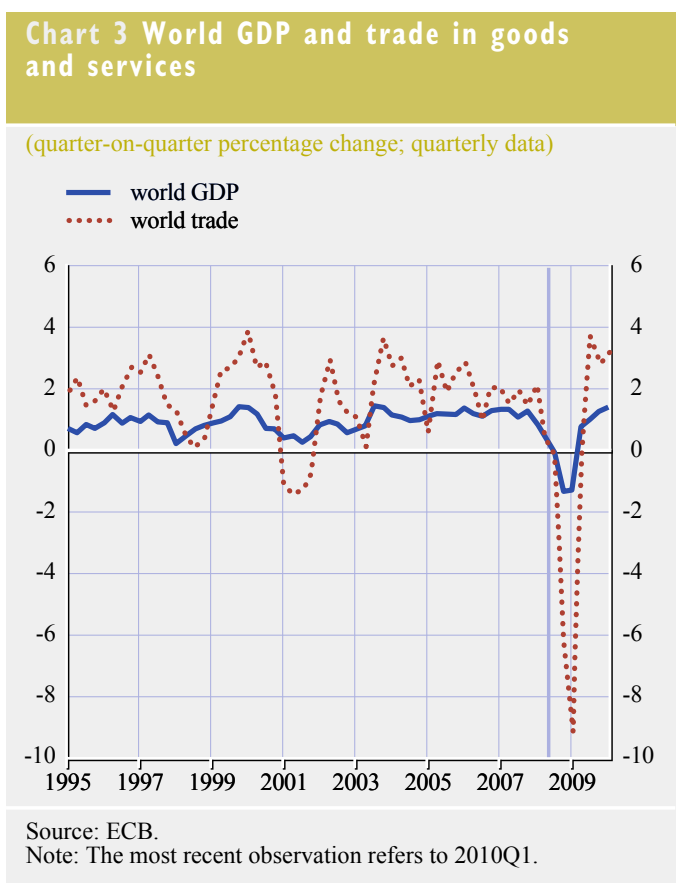

DEVELOPMENTS AT THE EURO AREA LEVEL

In line with the developments in world trade, euro area exports of goods ${ }^{5}$ also fell sharply. Euro area merchandise exports decreased by about 16\% between September 2008 and March 2009 (and by a total of 23\% from peak to through, also see Chart 2). The decline was initially more pronounced for intra-regional trade, which had started experiencing some weakness with the onset of the financial crisis in mid-2007. By contrast, the downturn in extra-euro area exports of goods was slower to materialise, showing the first signs of deceleration in mid-2008. By the beginning of 2009 , however, the decline in exports was fairly broad-based, with extra-euro area exports falling at a faster pace than intra-regional trade flows. From September 2008 to March 2009, extra-euro area exports slumped by about $18 \%$, while intraeuro area exports fell by approximately $15 \%$.

There were nevertheless large differences recorded between individual member countries (see Chart 4): exports in Malta, Slovakia and Finland fell by more than $12 \%$ in the first quarter of 2009, while exports from Ireland were relatively more resilient. Perhaps not surprisingly, countries that are relatively more open were associated with the severest export falls during this period (see Chart 5).

3 At this point it is worth differentiating between the apparent trade response, which is a simple average ratio of growth rates, and estimated trade elasticity, which measures the independent effect of changes in output on trade after accounting for other explanatory variables. In this case, we refer simply to the apparent trade response to world income

4 As indicated by Cheung and Guichard (2009), who claim that standard world trade equations cannot fully capture the downturn in trade in 2008Q4-2009Q1. Similarly, the Global VAR model by Bussiere, Chudik and Sestieri (2009) underpredicts the contraction in world trade. This is also illustrated by using the ECB's extra-euro area trade projection model (EXTRADE). Fluctuations in foreign demand - measured as a weighted average of imports of extra-euro area trading partners - have traditionally explained about 70 to $80 \%$ of the changes in export volumes, with relative export prices accounting for 10 to $15 \%$. The explanatory weight of these factors appears, however, to have decreased over the most recent downturn, resulting in a large residual component.

5 Unless otherwise stated, exports of goods are reported in volume terms. 


\section{Chart 4 Exports of goods}

(quarter-on-quarter percentage change; quarterly data

2008Q4

เทแกเ 2009Q1

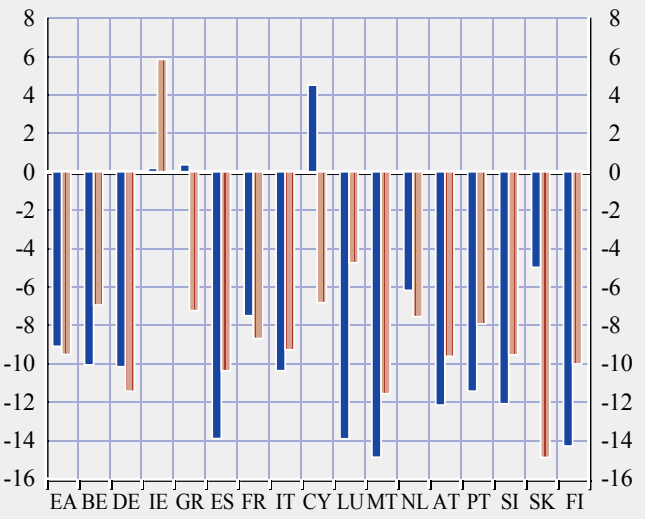

Source: Eurostat.

Note: Exports include both intra- and extra-euro area exports.

Chart 5 Relationship between the degree of openness and the change in export volumes

\section{(percentages)}

$\mathrm{x}$-axis: degree of openness

$\mathrm{y}$-axis: change in export volumes

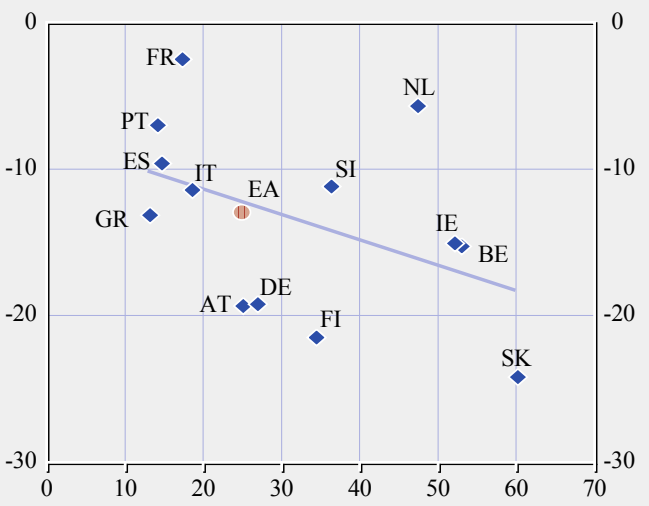

Source: ECB.

Notes: The blue line corresponds to a linear regression. Luxembourg, Malta and Cyprus were considered as outliers. The openness ratio is defined as the sum of exports and imports divided by the level of GDP (average over 1999-2009 period).
Chart 6 Extra-euro area exports to selected countries/regions

(goods volume indices: September 2008=100; 3-month moving average)

- total

..... United States

----- United Kingdom

— other EU countries OPEC

-.--- Asia

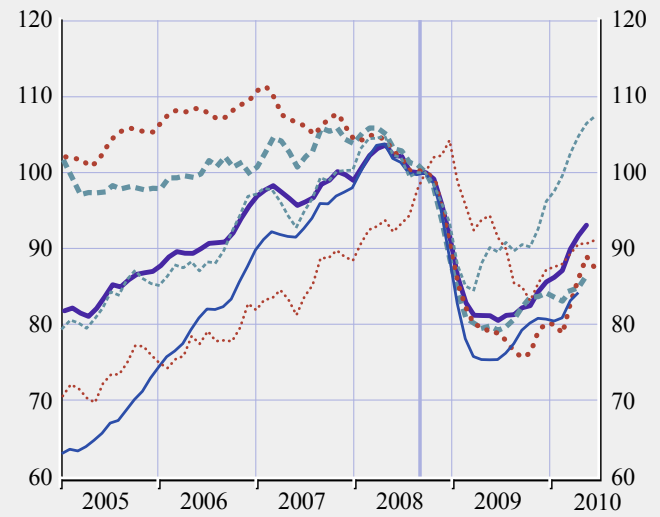

Source: Eurostat.

Notes: 'Other EU countries' includes non-euro area member countries except for the UK, Sweden and Denmark. The most recent observation refers to June 2010, except for total, 'United Kingdom' (May 2010) and 'Other EU countries' (April 2010).

In terms of its geographical composition, the fall in extra-euro area merchandise trade was also broad-based, relating to all major export markets (see Chart 6). Exports to the UK, the euro area's main trading partner, declined by 17\% between September 2008 and March 2009, while exports to other EU member countries in Central and Eastern Europe slumped by more than $24 \%$. Lower import demand from other advanced economies also had a severe impact on extra-euro area exports of goods. For instance, euro area exports to the US fell by more than $20 \%$ over the sample period, and exports to Japan slumped by almost $23 \%$. Although initially more moderate, the contraction in exports to emerging countries accelerated at the start of 2009, with some notable differences across regions. While exports to Russia and Latin America fell dramatically, by more than $40 \%$ and roughly $30 \%$ respectively during this period, exports to Asia decreased by around $10 \%$. 
Also importantly, the trade downturn was characterized as well by notable changes in the composition of trade flows. Firstly, the fall in merchandise trade was considerably more pronounced than the decline for trade in services. Although export growth for goods tends to be very similar historically to that of services, trade in goods was hit particularly hard by the slump in global economic activity. By contrast, the services sector proved to be more resilient. Secondly, the decline in manufactured goods was particularly pronounced during this period (more than 25\%, see Chart 7). Export volumes of machinery and transport equipment fell roughly by the same magnitude, thus also reflecting the difficult situation of the automobile sector. Thirdly, the slump in merchandise trade was also uneven across categories of goods. Overall, exports of capital and intermediate goods contracted to a much greater extent than exports of consumer goods (see Chart 8). Euro area exports of capital goods to destinations outside the euro area declined by approximately $26 \%$

\section{Chart 7 Extra-euro area exports of goods by selected sectors}

(volume indices: September 2008=100; 3-month moving average)

total trade

..... crude materials (excluding food and fuel) (SITC 2)

n-mergy (SITC 3 )

— chemicals (SITC 5) manufactured goods (SITC 6 )

...- machinery and transport equipment (SITC 7)

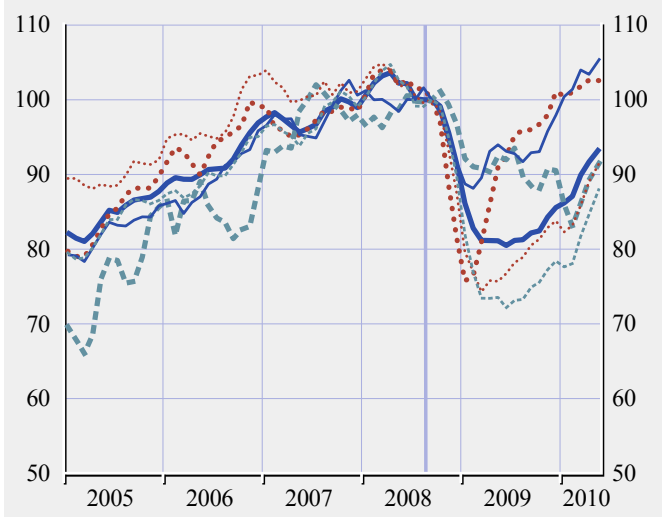

Source: Eurostat

Note: The most recent observation refers to May 2010 between September 2008 and March 2009, and exports of intermediate goods declined by almost $17 \%$. By comparison, the decline in extra-euro area exports of consumer goods was relatively more muted, at about $10 \%$ over the same period. However, if we consider not only exports of consumer goods, but also of petrol and cars (which are normally denoted as consumption goods), the fall becomes more pronounced, closer to $16 \%$.

These different developments across sectors and categories of goods may usefully explain the differences across the euro area's member countries. While some of this divergence may reflect in part the geographical orientation of an individual country's exports, relative product specialisation appears to have played a prominent role. As the fall in demand was particularly pronounced for intermediate and capital goods, countries that mainly specialise in these products, for instance Finland, Austria and Germany, were hit harder by the global downturn.

\section{Chart 8 Extra-euro area exports of goods by product categories}

(volume indices: September 2008=100; 3-month moving average) — total trade .... capital goods

-1- intermediate goods

— consumer goods consumption goods

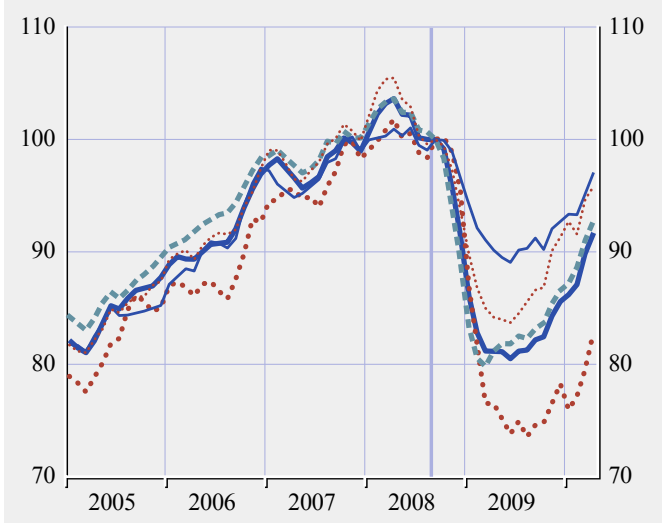

Source: Eurostat.

Notes: Consumption goods include consumer goods, cars and petrol. The most recent observation refers to April 2010. 


\subsection{MAIN FACTORS BEHIND THE DOWNTURN IN TRADE: WHAT HAS MADE THIS CYCLE SO EXCEPTIONAL?}

Overall, the collapse in trade appears to have been driven primarily by a sharp deterioration in global demand conditions during the winter of 2008/09. The deepening of the financial crisis in the autumn of 2008 generated a substantial loss in confidence among households and firms, which opted to postpone any likely consumption and investment expenditure. ${ }^{6}$ Consequently, global economic activity declined abruptly, as did global demand for traded goods.

Although a decline in foreign demand remains the chief explanation for the downturn in trade, the severity and synchronisation of the slump in trade, as well as the apparent increase in the sensitivity of trade to GDP compared to previous recessions, suggests that factors other than the decline in final demand are likely to have played a role. Some of those factors are reviewed below.

\section{COMPOSITION OF THE GLOBAL DEMAND SHOCK}

One of the key factors in explaining the disproportionately large decline in trade relative to output is the composition of the global demand shock. In line with similar developments in euro area exports, the slump in global demand was very much concentrated on the manufacturing sector, and thus on goods which are typically tradable and, as such, tend to have a higher share of trade as opposed to GDP. As the collapse in demand following the fall in confidence levels concentrated mainly on capital and consumer durable goods, ${ }^{7}$ this also triggered lower demand for related intermediate goods, which may also partly explain why the recent shock had a substantially bigger impact on trade rather than GDP. ${ }^{8}$

Furthermore, the discrepancy between developments in trade and activity can also be partly explained by the different import intensities of the expenditure components. The global economic downturn and its initial policy response led to a shift away from higher import-intensive GDP expenditure components such as investment and exports over to other, less import-intensive components such as government consumption (as part of the approved fiscal stimulus packages). This view is corroborated by the findings of Anderton and Tewolde (2009), who argue that the fall in high import-intensive investment and exports expenditure can explain a significant proportion of the recent decline in world imports.

Finally, the inventory cycle during the downturn in global activity also adversely affected global trade developments. More specifically, the response of firms to the global financial crisis also had a significant impact on inventory levels, which exacerbated the impact of the shock on final demand. As global sales plummeted, firms scaled down their production, mainly drawing from their existing inventories of intermediate goods. At the same time, they also ran down their inventories of finished goods in order to restore their inventory-to-sales ratios to more normal levels.

\section{INCREASED ROLE OF INTERNATIONAL SUPPLY CHAINS}

Another possible factor behind the increase in trade sensitivity to fluctuations in demand may be linked to structural changes related to globalisation. Looking at the upward trend in the share of world trade in world output (which can be defined as a measure of the degree of openness of the global economy, see Chart 9), this seems to point to long-term income elasticity greater than one. The change in the curve towards the late 1980s suggests that this elasticity is rising over time. Freund (2009) estimates that the elasticity of world trade to world income has indeed increased over recent decades, from 1.9 in the

6 According to Bems et al (2010), 70\% of the collapse in trade in 2008/09 can be explained by changes in final demand.

7 Also called "postponeable" goods.

8 Furthermore, the synchronised and widespread nature of the downturn in trade has also contributed significantly to its decline. Since almost every country or region in the world experienced a decline in trade simultaneously, external demand was less able to act as shock absorber, as the fall in demand from certain trade partners cannot be compensated for by shifting markets. 
Chart 9 World openness ratio and index of global Vertical Supply Integration

index of vertical supply integration $(1980=1)$ world trade/world GDP (right-hand scale)

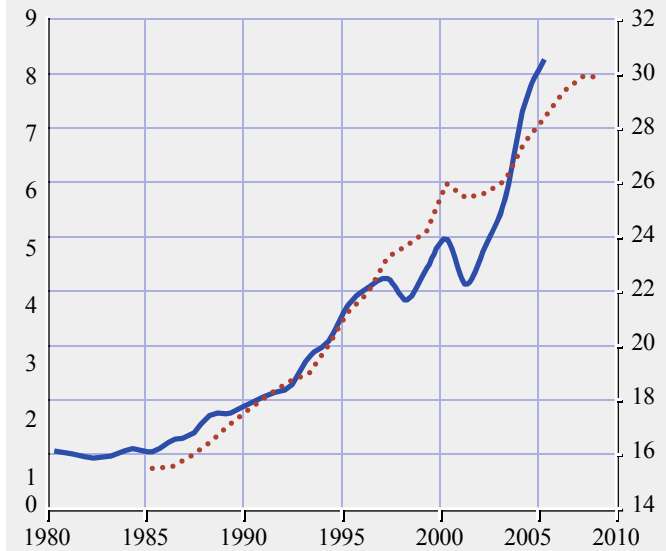

Source: Authors' calculations based on IMF data and Amador and Cabral (2009)

Notes: This index is based on a measure of imports of intermediate goods with aboveaverage exports of a related item, using countries' input-output tables. The most recent item, using countries input-output tables. The most recent observations refer to 2005 for the index of vertical integration

1960 s to 3.7 in the previous decade, with trade responsiveness estimated to be even higher during global downturns (at around 4.7).

This increase in the elasticity of word trade to world income can be partly explained by an acceleration in globalisation trends over recent years, particularly an increase in vertical supply integration. The globalisation of production processes, facilitated by an overall reduction in trade barriers and transportation costs, has led to considerable growth in vertical supply integration over recent years (see also Chart 9), which is estimated to have accounted for about one-third of total trade growth in the last 20 to 30 years (Hummels et al, 2001). This implies that goods are now manufactured via complex international networks, with firms in different countries working on different stages of the production of the same good in an international supply chain. These increasingly complex international supply chains may have acted as powerful transmission and propagation mechanisms for the recent trade contraction, ${ }^{9}$ which also explains the high degree of synchronisation across countries. ${ }^{10}$

In addition, the increased presence of supply chains may also have contributed to the synchronisation and propagation of the fall in trade through a different channel. With deteriorating credit conditions, firms may have become more restrictive in providing informal finance along the supply chain, generating bottlenecks and even disruptions within it. Furthermore, the downsizing of production by (and even bankruptcy of) some large global players may have left smaller and less diversified suppliers of such products in a difficult situation. As shown in Chart 10, the recent fall in trade was more severe for countries that have been growing rapidly, or are characterised by higher proportions of vertical specialisation (Miroudot and Ragoussis, 2009 and Levchenko et al., 2009), indicating that the increase in vertical supply integration may indeed have acted as an additional propagation mechanism for the collapse in trade. Moreover, differences in production-sharing arrangements may hint at a further explanation of why trade with different countries and regions was affected to varying degrees.

Overall, it remains very difficult to evaluate the nature and magnitude of the contribution of the increased presence of international supply chains to the downturn in trade. In particular, it is hard to assess if this effect was due mainly

9 Another possible explanation for the role of increased vertical supply integration in explaining the wedge between trade and GDP developments relates to differences in measurement. More specifically, while foreign trade statistics account for the value of each transaction (e.g. the various parts of a car), GDP data only measure the value added (e.g. assembling the actual car). Consequently, intermediate components used in production are captured in trade flows but not in GDP.

10 In more detail, as supply chains are in constant communication to ensure that the flow of parts and components matches precisely the demand for finished goods, firms are now quicker to react and adjust their production levels to any changes in demand, rapidly propagating the effect of a shock across firms and borders. See also Bems et al (2009). 


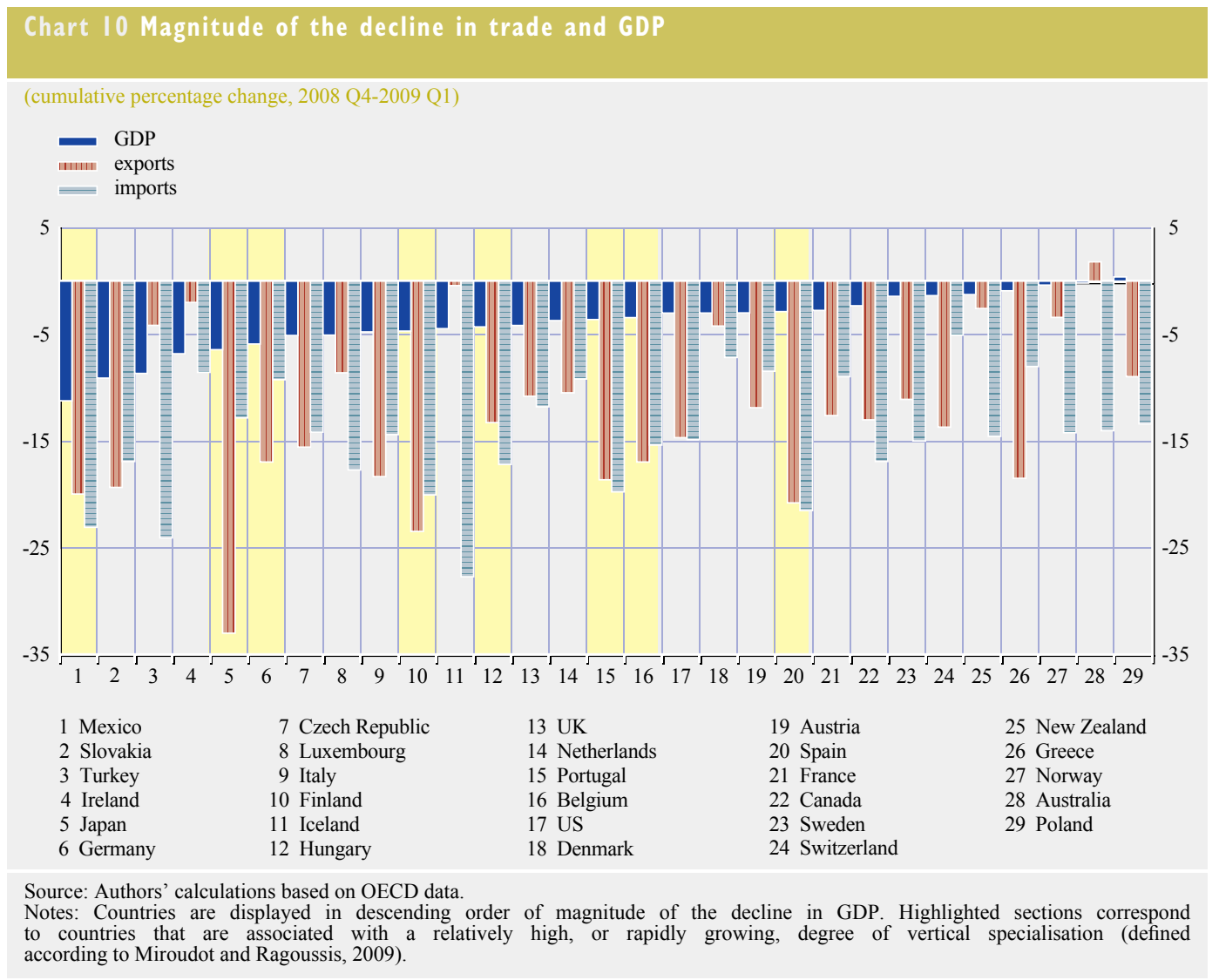

to disruptions or bottlenecks in these global supply chains or simply a sign that these chains are now quicker to adjust their supply to current demand conditions. Notwithstanding this aspect, increased vertical supply integration remains an important factor in explaining the speed of propagation of the shock and the high degree of synchronisation between the different countries.

\section{SHORTAGE OF TRADE FINANCE}

Lastly, the rapid tightening in global financial markets following the financial turmoil generated a shortage of trade finance that may have further dampened trade activities. It is estimated that approximately $90 \%$ of world trade relies on some form of trade finance, which potentially implies that an increase in the costs of trade finance may have indeed exacerbated the trade contraction. Auboin (2009) described a USD 25 billion shortfall in trade credit in November 2008. According to World Bank estimates, this may have contributed to between roughly $10 \%$ and $15 \%$ of the decline in world trade since the second half of 2008. Against this background, governments and multilateral institutions have undertaken various measures to support trade finance. In particular, the G-20 agreed to make available an overall USD 250 billion in short-term trade finance over the period 2009/11.

However, and in spite of having been one of the first factors brought forward to explain the recent collapse in trade, there are still some doubts over the specific contribution made by the drying-up of trade finance. Survey-based evidence (such as the IMF/Bankers' Association for Finance and Trade survey) suggests that the decline in trade finance levels is not only related to supply-side disruptions, but also to a decline in the demand for trade finance, as trade activities decreased at the same time. 
Nevertheless, empirical evidence has shown that exports of firms reliant on external finance were hit particularly hard by the crisis $^{11}$, suggesting that the financial crisis generated supply-side disruptions to global trade. While increased vertical supply integration may have helped to mitigate this impact (by providing liquidity along the supply chain), this does not appear to have been sufficient to replace bank-intermediated trade finance. 


\section{THE EURO AREA'S EXPORT PERFORMANCE AND COMPETITIVENESS: PRE-CRISIS TRENDS AND THE IMPACT OF THE FINANCIAL CRISIS}

The global downturn in trade during 2008/09 had a severe impact on euro area exports. While partly reflecting the relatively high openness of the euro area economy, this has also prompted increasing concerns about the competitiveness of the euro area. In order to contribute to this debate, this chapter assesses the impact of the crisis on euro area competitiveness, particularly against the background of previous trends, and points to a number of challenges that need to be addressed timely.

\section{I MEASURING COMPETITIVENESS: SOME BASIC BUILDING BLOCKS}

In spite of the term "competitiveness" being commonly used in the public debate, there is no agreed way to define and measure it. Opinions tend to diverge rather widely on which concept of competitiveness is more appropriate and under which circumstances. Partly as a result of this, a very broad range of indicators is available.

Traditional approaches consider successful export performance - either in terms of export growth or export market share - as the ultimate sign of competitiveness. Since relative prices are an important factor shaping the export performance of an economy, particularly in the short term, relative export prices or the real effective exchange rate constitute standard indicators of cost and price competitiveness. To construct the latter, several deflators are used, such as unit labour costs (ULC, either in the manufacturing sector alone or in the total economy), consumer price and producer price indices (CPI and PPI) and GDP deflators. For individual euro area countries, the ECB calculates Harmonised Competitiveness Indicators (HCI, also based on different deflators), which correspond to real effective exchange rates computed on the basis of national trade weights. Conceptual differences across deflators notwithstanding, the trends in price and cost competitiveness developments appear to be broadly invariant to the deflator used, both for the euro area as a whole and for its member countries.

However, while for most euro area countries price competitiveness has been a critical factor in shaping relative export performance with respect to major direct competitors - most notably developed economies - other non price-related factors play a part. Above all, a country's export performance is affected by the geographical and sectoral composition of its exports. More specifically, it will depend on the extent to which a country specialises in rapidly growing sectors or markets. For the individual euro area countries, the geographical orientation of exports has an additional dimension, with the shares of intra- and extra-euro area trade capturing the degree of openness vis-à-vis other member countries and the rest of the world respectively. The sectoral specialisation of an economy is often assessed by means of Balassa Indices of revealed comparative advantage. More generally, non-price competitiveness comprises the structural and technological aspects of competitiveness. In this context, factors such as research and innovation, infrastructures, as well as the regulatory and tax framework of a country, are critical because they affect the prospects of achieving higher productivity growth and thus competitiveness in the medium and longer term. However, while the traditional approach acknowledges the relevance of such factors to a country's export performance, their interaction with price competitiveness factors is not fully spelled out. Non-price competitiveness components are often treated more as a residual rather than a systematic critical element of export performance. This implies, for instance, that factors such as product quality and branding, which play an important role in the export performance of advanced economies, are not taken fully into account. More generally, the traditional approach tends to overemphasise export performance, while, at best, trade has 
to be considered purely as a means to achieve welfare maximisation, as represented by higher value added per capita or lower unemployment.

Against this background, we have argued that a more holistic approach to competitiveness is needed to complement the results of the traditional analysis and, in particular, to understand more clearly what factors determine competitiveness in the medium and longer terms (di Mauro and Forster, 2008). As in our earlier work, we will rely here on a fairly general definition of competitiveness, defined as the ability of firms to compete successfully in international markets, the ultimate goal being to raise a country's welfare and living standards. More specifically, in line with Ottaviano, Taglioni and di Mauro (2009), we use a model-based framework which defines a country's competitiveness as the productivity of the firms located within it (for more details, see Annex 3). In this context, the most competitive economy is considered to be the one with the best prospects for "generating" highly productive firms. Such a country will make efficient use of its resources, increasing the welfare of its citizens. The ability of an economy to generate highly productive firms relates to three broad sets of factors: (i) firm-level factors, e.g. the technological ability of firms to utilise given factor endowments; (ii) structural characteristics, such as the degree of labour- and product-market flexibility, technological diffusion, innovation, and demand conditions; (iii) the geographical position of the country and the extent of trade frictions. Aggregate productivity will generally rise along with a country's openness to foreign competition. Trade liberalisation acts as a selection mechanism that reallocates resources and revenues to the more productive firms and forces out the least productive ones, since the latter cannot bear the fixed costs related to doing business abroad.

By unravelling the relative importance of the different sets of factors, the framework also yields a ranking of countries in terms of their firms' productivity. To this end, two types of competitiveness measures are calculated. The first - "overall" competitiveness corresponds to the recorded productivity of firms that are supposedly dependent on all sets of factors identified by the model. The second - "producer" competitiveness measures the impact of technology and institutional factors alone after filtering out the impact of geographical location, thus encapsulating the ability of countries to generate highly productive firms regardless of their respective market size and level of accessibility.

\subsection{PRE-CRISIS TRENDS IN EURO AREA EXPORTS AND COMPETITIVENESS}

In order to put the developments since the start of the crisis into perspective, this section reviews the main pre-crisis trends in the competitiveness of the euro area as a whole and of the euro area countries. Negative impacts of the crisis notwithstanding, the euro area over the last decade had been increasingly challenged by structural changes related to globalisation, particularly the emergence of new major low-cost competitors like China and India. Unless a break from, or even a reversal in, previous globalisation trends is assumed, those challenges will also remain significant going forward

\section{EXPORT MARKET SHARES AND PRICE \\ COMPETITIVENESS}

Developments in euro area trade and competitiveness in the decade preceding the financial crisis were profoundly shaped by globalisation trends. Against the backdrop of the rapid and increasing integration into the world economy of new global players such as China, India and other emerging economies, the euro area has increasingly imported from cheaper suppliers in emerging markets and registered a strong upswing in exports to these countries. These benefits notwithstanding, the emergence of cost-competitive countries as major exporters also increased the degree of competition faced by the euro area and other advanced
3 THE EURO AREA'S EXPORT PERFORMANCE AND COMPETITIVENESS: PRE-CRISIS TRENDS AND THE IMPACT OF THE FINANCIAL CRISIS 


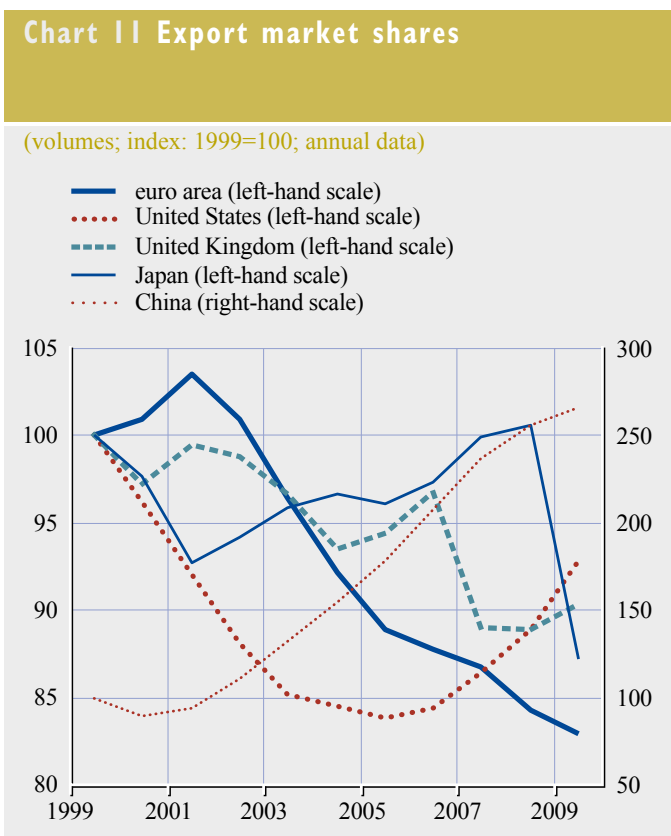

Source: Authors' calculations based on IMF, ECB and Eurostat data. Notes: Real export market share corresponds to the volume of exports divided by a country-specific weighted average of the import volumes of major trading partners. The most recent observation refers to 2009 .

industrialised economies, resulting in losses of their export market shares - in contrast to the dramatic increase in shares for new entrants like China (see Chart 11).
Although the decline in shares is partly mechanical, the euro area registered bigger losses than other developed economies. This appears to be mainly associated with unfavourable trends in price competitiveness. If measured in terms of relative export prices, euro area price competitiveness deteriorated by around 10\% between 1999 and 2008 (based on the average over the three pre-crisis quarters, see Chart 12 , left panel). By contrast, the United States, Japan and, to a lesser extent, the United Kingdom all recorded significant gains in price competitiveness over the same period, broadly in line with exchange rate trends (see Chart 12, right panel). Those gains may have contributed to a partial recovery of the export market shares of the respective countries. Notwithstanding this aspect, the extent of market share deterioration for the euro area compared to its major trading partners points to the critical importance of other, non-price factors, which we will consider in more detail in both the following and later sections.

This is also apparent when looking at the individual euro area countries, where pre-crisis developments in export market shares tended in general to reflect trends in price competitiveness, albeit with a few notable exceptions. On the one

\section{Chart 12 Price competitiveness and exchange rates}
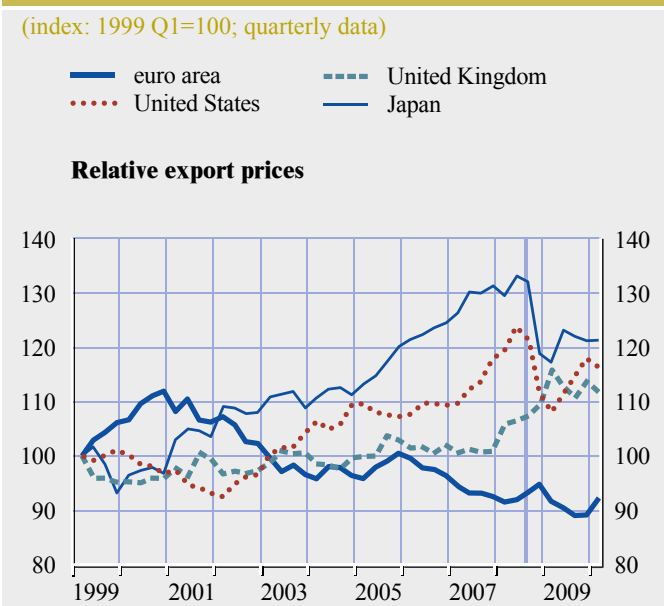
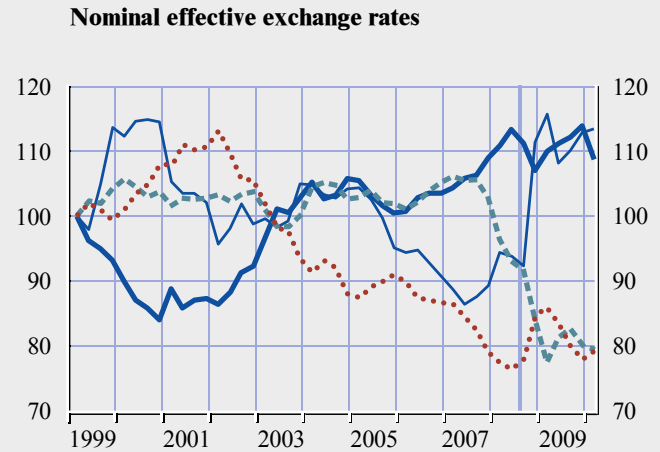

Sources: Authors' calculations based on IMF, ECB and Eurostat data.

Notes: Relative prices are defined as the ratio of a weighted sum of competitors' export prices to domestic export prices (both expressed in domestic currency). Lower values denote a loss in competitiveness. For nominal effective exchange rates, an increase indicates an appreciation. The most recent observation refers to 2010Q1. The additional vertical line, in bold, corresponds to September 2008 (i.e. the collapse of Lehman Brothers). 


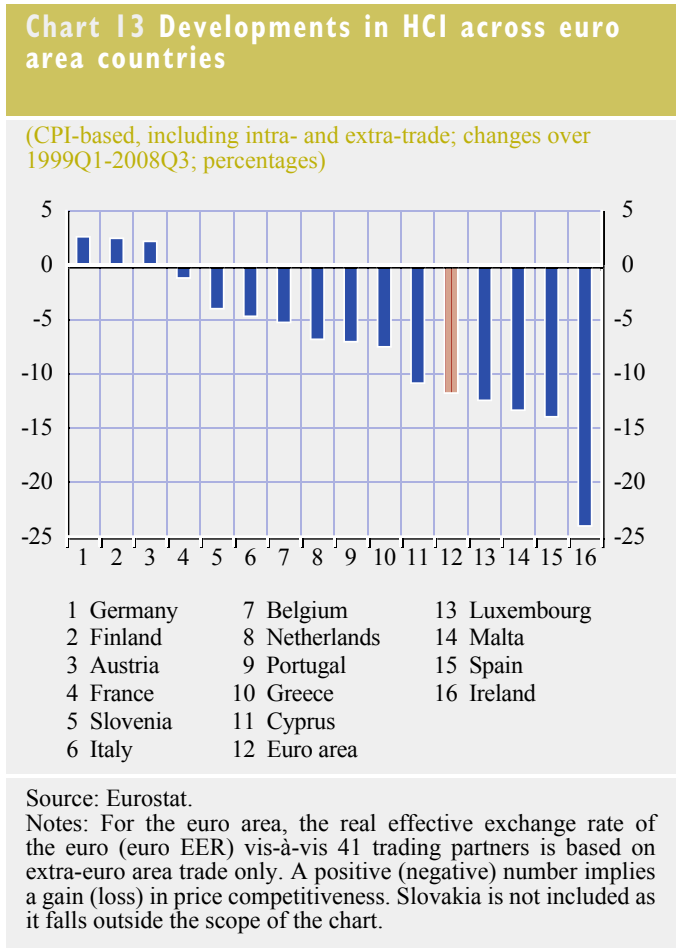

hand, gains in price competitiveness, particularly in Germany, were associated with gains in market share, irrespective of the measurement method used - CPI-deflated real effective exchange rate (HCI) or relative export prices (see Charts 13 and 14, as well as Annex Chart A1). On the

\section{Chart I 4 Developments in export market shares and price competitiveness}

\section{(changes over 1999Q1- 2008Q3; percentages)}

$\mathrm{x}$-axis: change in relative export prices $\mathrm{y}$-axis: change in export market shares

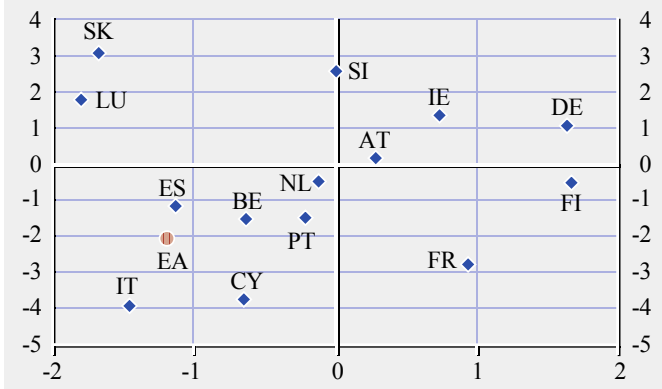

Source: ECB.

Notes: Price competitiveness is represented by relative export prices (competitors' export prices divided by a country's export prices). A positive (negative) number implies a gain (loss) in price competitiveness. other hand, losses in price competitiveness as recorded in most of the countries - were generally associated with losses in market share that were particularly severe in the case of Italy, Spain, Malta, Cyprus and Belgium. In a number of countries, however, factors other than prices and costs must have been at work: in France, for instance, where the dramatic drop in market shares could not be related to developments in price competitiveness; and in Luxembourg and Slovakia, where a sharp decline in price competitiveness was associated with substantial gains in market share.

\section{SECTORAL EXPORT SPECIALISATION}

One non-price factor, which has increasingly affected the export performance of the euro area in the context of globalisation, is export specialisation. Looking at the Balassa Indices (BI) of revealed comparative advantage, ${ }^{12}$ the euro area has been specialising mainly in medium/ high-tech exports, or, in terms of factor intensity, in capital-intensive, research-intensive and labour-intensive goods (see Tables 1 and 2). ${ }^{13}$ This has contrasted in part with other advanced economies that have been specialising in exports of high-tech products and are relatively more

12 The Balassa Index (BI) is calculated in the following way:

$$
B I=\frac{X_{c s}}{X_{w s}} \times \frac{X_{w}}{X_{c}}
$$

where $X_{c s}$ refers to a country's exports in sector $s, X_{c}$ to a country's total exports, $\mathrm{X}_{\mathrm{ws}}$ to world exports in sector $\mathrm{s}$ and $\mathrm{X}_{\mathrm{w}}$ to total world exports. The BI can take values between "zero" and "infinity"; a country is said to specialise in a sector s if the BI for that sector is higher than 1. The Balassa Index does not show a constant maximum or average in different years, which implies that cross-country dynamic analysis should be performed with caution. Nevertheless, overall qualitative results should not be affected. It should, however, be kept in mind that the index has many pitfalls and has been subject to various critiques (for more details, particularly on the classification of exports by technological content, see di Mauro and Forster (2008)). Efforts have been made to compute indices of trade specialisation that overcome some of these problems, yet these alternatives often suffer from other drawbacks (see for example, De Benedictis and Tamberi (2001)). Therefore, the BI remains the most popular export-based measure of specialisation. In line with the OECD (2005), it is customary to analyse the BI by aggregating different product types into four main categories based on their technological content.

13 In line with the OECD, it is customary to analyse the BI by aggregating different product types into four main categories based on their technological content (for more details, see Annex B).
3 THE EURO AREA'S
EXPORT PERFORMANCE
AND COMPETITIVENESS:
PRE-CRISIS TRENDS
AND THE IMPACT OF
THE FINANCIAL CRISIS 


\begin{tabular}{|c|c|c|c|c|c|}
\hline \multicolumn{6}{|c|}{ (Balassa Index; average $2005 / 08$, based on values in USD) } \\
\hline & EA & US & JP & UK & China \\
\hline \multicolumn{5}{|l|}{ High-technology } & 1.5 \\
\hline $\begin{array}{l}\text { Medium-high-technology } \\
\text { industries (MHT) }\end{array}$ & 1.2 & 1.1 & 1.5 & 1.0 & 0.7 \\
\hline $\begin{array}{l}\text { Medium-low-technology } \\
\text { industries (MLT) }\end{array}$ & 0.8 & 0.8 & 0.9 & 0.7 & 0.6 \\
\hline $\begin{array}{l}\text { Low-technology } \\
\text { industries (LT) }\end{array}$ & 0.9 & 0.8 & 0.4 & 0.9 & 1.2 \\
\hline \multicolumn{6}{|c|}{$\begin{array}{l}\text { Source: Authors' calculations based on CHELEM data. } \\
\text { Notes: High-tech (HT), medium/high-tech (MHT), medium/ } \\
\text { low-tech (MLT) and low-tech (LT), based on the OECD } \\
\text { classification. Euro area refers solely to extra-euro area exports. }\end{array}$} \\
\hline \multicolumn{6}{|c|}{$\begin{array}{l}\text { Table } 2 \text { Revealed comparative advantage } \\
\text { by factor intensity }\end{array}$} \\
\hline \multicolumn{6}{|c|}{ (Balassa Index; average $2005 / 08$, based on values in USD) } \\
\hline Exports are predominantly & EA & US & UK & JP & China \\
\hline Raw material intensive & 0.5 & 0.7 & 0.6 & 0.1 & 0.4 \\
\hline Labour intensive & 1.1 & 0.8 & 1.0 & 0.5 & 2.3 \\
\hline Capital intensive & 1.2 & 0.9 & 1.1 & 1.6 & 0.3 \\
\hline Research intensive & 1.1 & 1.4 & 1.2 & 1.4 & 1.0 \\
\hline
\end{tabular}

specialised in exports of research-intensive goods. At the same time, other advanced competitor countries do not have a revealed comparative advantage in labour-intensive products. However, there are several caveats in relation to these measures. First, some products are difficult to classify in terms of factor intensity as they utilise several factors of production. Second, the classifications may be misleading if a country focuses primarily on the labour-intensive stages of a predominantly research-intensive or high-tech good. This may apply to China, which appears to be even more specialised in high-tech industries than the euro area, the United States, the United Kingdom or Japan (see Table 1). This does not necessarily stem from China's superiority in high-tech research, but rather may show China's growing importance as an assembly centre, with foreign firms outsourcing the labour-intensive parts of their research-intensive production to China.

Nevertheless, therearealso significant differences between individual euro area member countries (see Table 3 and Annex 2). Ireland, for instance, has been largely specialising in exports of high-tech products, while Greece and Portugal have continued to specialise extensively in exports of low-technology products.

In general, although it is not easy to assess the role of export specialisation in export performance, a look at changes to the euro area's export specialisation over time reveals some signs of weak competitive fundamentals. On the one hand, the specialisation in medium/ high-tech exports has rather supported export performance over the pre-crisis period, since world demand was fairly strong in those sectors (e.g. machinery and equipment, motor vehicles and transport equipment, see Chart 15). Some more mature, low-tech sectors (such as textiles and furniture) appear to have been losing ground,

\begin{tabular}{|c|c|c|c|c|c|c|c|c|c|c|c|c|c|c|}
\hline \multicolumn{15}{|c|}{ (Balassa Index, average 2005/08, based on values in USD) } \\
\hline & EA & BE & DE & IE & GR & ES & FR & IT & NL & AT & PT & SI & SK & FI \\
\hline High-technology industries (HT) & 0.8 & 0.7 & 0.8 & 2.1 & 0.5 & 0.4 & 1.0 & 0.4 & 0.5 & 1.2 & 0.5 & 0.6 & 0.6 & 1.0 \\
\hline Medium-high-technology industries (MHT) & 1.2 & 1.0 & 1.4 & 0.9 & 0.5 & 1.3 & 1.1 & 1.3 & 1.2 & 0.8 & 0.9 & 1.5 & 1.4 & 0.9 \\
\hline Medium-low-technology industries (MLT) & 0.9 & 1.4 & 0.8 & 0.2 & 1.6 & 1.1 & 0.8 & 1.0 & 1.0 & 0.9 & 1.0 & 0.7 & 1.0 & 1.2 \\
\hline Low-technology industries (LT) & 1.0 & 1.0 & 0.8 & 0.7 & 1.7 & 1.1 & 0.9 & 1.1 & 1.0 & 1.2 & 1.5 & 1.1 & 0.8 & 1.0 \\
\hline
\end{tabular}

Source: Authors' calculations based on CHELEM data

Notes: High-tech (HT), medium-high-tech (MHT), medium-low-tech (MLT) and low-tech (LT), based on the OECD classification. Euro area refers to both intra and extra-euro area exports 


\section{Chart 15 Change in euro area export specialisation and world trade growth}

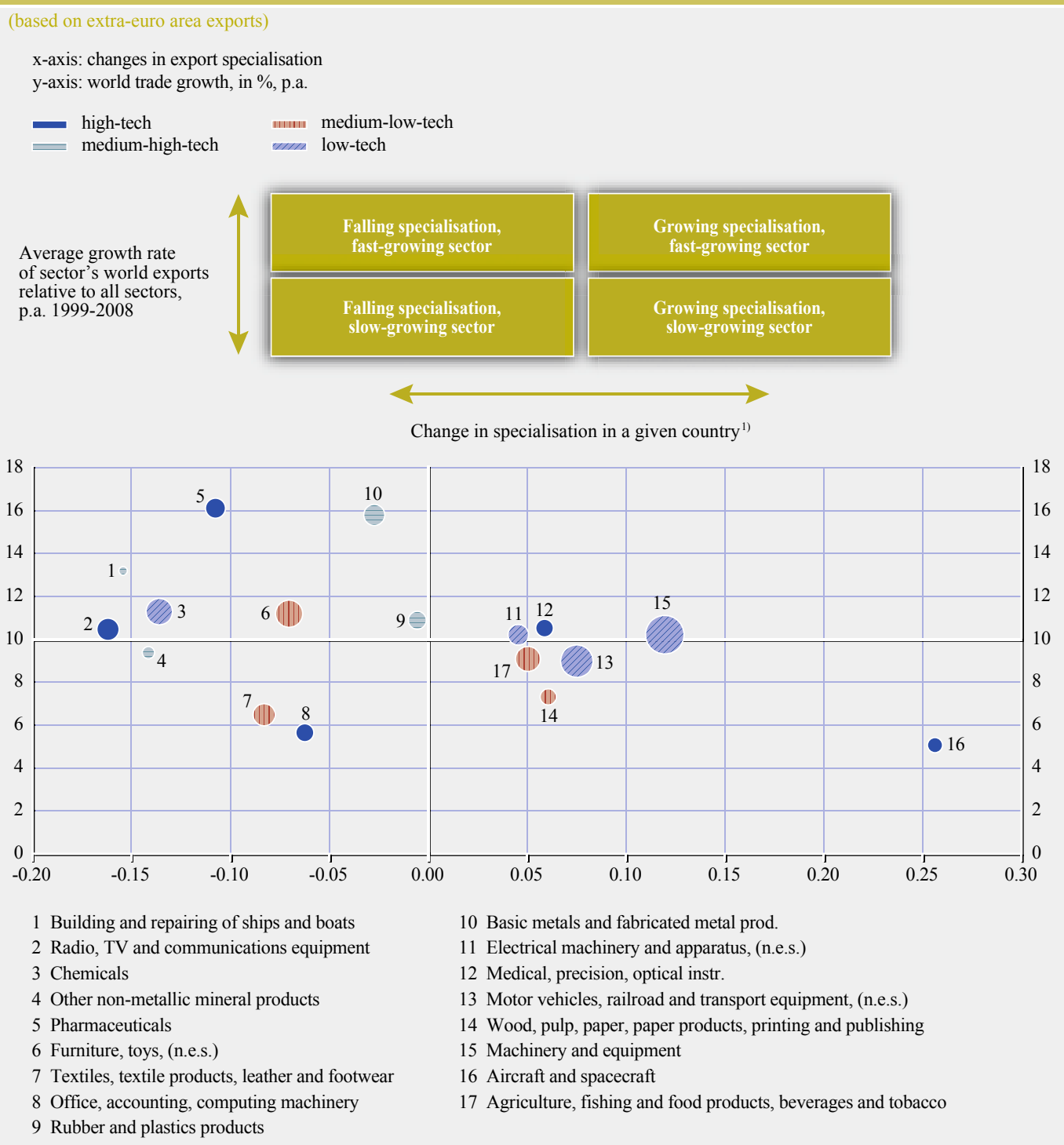

Source: Authors' calculations based on CHELEM data.

Notes: The change in export specialisation is defined as the change in the Balassa Index of revealed competitive advantage between $1998 / 2000$ and 2006/08. Bubble size is determined by the average share of exports in total extra-euro area exports over the 1999/2008 period. The $\mathrm{x}$-axis and the $\mathrm{y}$-axis intersect at $10.0 \%$, the average annual world trade growth over the 1999/2008 period.

roughly in line with the perceived comparative advantage of the euro area. On the other hand, it is noticeable that instead of showing increasing specialisation in fast-growing high-tech sectors (such as pharmaceuticals and radio, TV and communications equipment), euro area exporters have actually moved away from those sectors, with the notable exception of medical, precision and optical instruments.
3 THE EURO AREA'S

EXPORT PERFORMANCE

AND COMPETITIVENESS:

PRE-CRISIS TRENDS

AND THE IMPACT OF

THE FINANCIAL CRISIS
At the same time, the euro area has shown neither a decline in its specialisation in labour-intensive products nor the expected shift towards more research-intensive production a trend that, on the contrary, was not only seen in other advanced economies, but also in the case of China (see Chart 16). While this could imply either that the euro area had less of an incentive to diversify away from these sectors, 


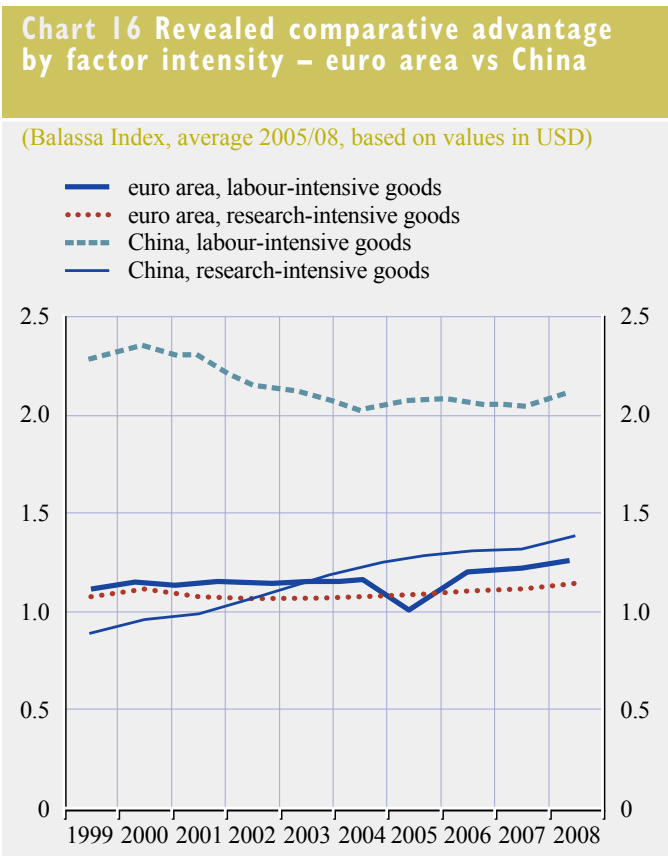

Source: Authors' calculations based on CHELEM data Note: Data for the euro area refers to extra euro area exports.

on the more negative side it could also denote that structural impediments have hampered shifts in production/export patterns.

In general, medium/high-tech sectors appear to have been relatively less prone to direct competition from China. However, while this is true for the euro area as a whole, there are considerable differences across euro area member countries. An examination of the degree of overlap in export specialisation patterns between China and the euro area countries for 72 industries reveals that countries exhibiting modest specialisation similarity with China (namely Ireland, Netherlands, Belgium and Germany) fared relatively well over recent years in terms of export market shares (see Chart 17). On the other hand, countries which have lost market shares (namely Portugal, Italy and Greece) are also the ones with a higher degree of overlap. This analysis, however, is inconclusive for a number of countries, particularly France, which, in spite of having

\section{Chart 17 Degree of overlap in export} specialisation between selected economies and China

(average overlap, 2005/08; percentages)

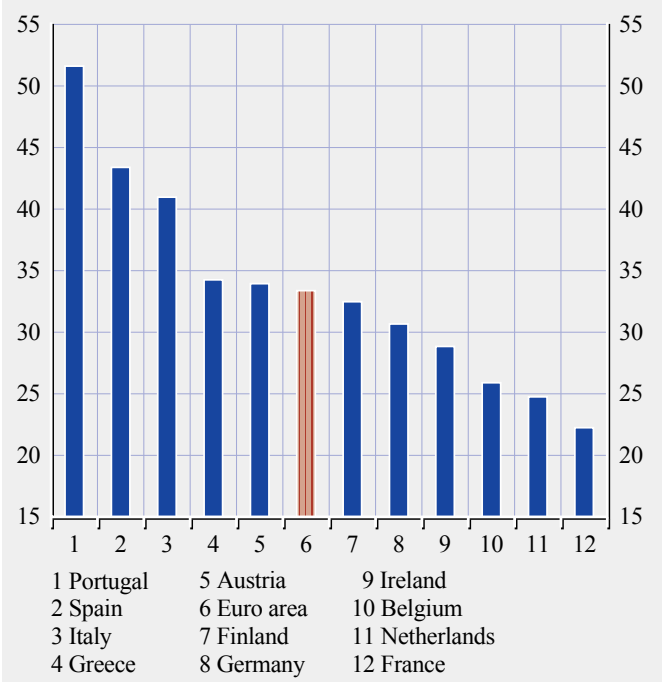

Source: Authors' calculations based on CHELEM data.

recorded the fewest overlaps, experienced substantial losses in terms of market shares. ${ }^{14}$

Going forward, given the increasing importance of low-cost competitors, some countries may be forced to adjust their export portfolio. In addition, unchanged export specialisation patterns might also reflect a degree of structural rigidity that could potentially dampen euro area firm productivity. Aggregate measures of productivity partly corroborate this concern. Euro area labour productivity over recent years appeared to be rather sluggish with respect to major

14 Again, it is important to remember the caveats inherent to this analysis. While the growing presence of China and other emerging economies in many markets can be an indication of additional competitive pressure, differences in the quality of various products across different exporters should also be accounted for. Taking the example of textiles, the ongoing strong specialisation of some countries like Italy may also reflect comparative advantages in producing higher quality and a wide variety of these products. Recent evidence shows that in the past decade euro area countries and other EU member states have gained market shares in some higher-price and higher-quality segments (see Curran and Zignago, 2009). 


\begin{tabular}{|c|c|c|c|}
\hline \multicolumn{4}{|c|}{ (annual average growth) } \\
\hline & 1980-1989 & 1990-1999 & 2000-2007 \\
\hline Euro area & 2.5 & 1.8 & 1.3 \\
\hline US & 1.2 & 1.5 & 1.9 \\
\hline Japan $^{1)}$ & 4.1 & 2.5 & 2.1 \\
\hline UK & 1.8 & 2.6 & 1.7 \\
\hline
\end{tabular}

Source: Authors' calculations based on EU KLEMS. Notes: The euro area corresponds to the EU KLEMS aggregate "Eotes: The euro area corresponds to the EU KLEMS aggregate of 1 January 2001

1) Data for Japan only as far as 2006

competitors, most notably the United States (see Table 4). Labour productivity growth (measured as average annual growth of gross value added per hour worked) in the euro area actually declined from $2.5 \%$ during the 1980 s to $1.8 \%$ in the $1990 \mathrm{~s}$ and $1.3 \%$ thereafter, in spite of the increased openness of the euro area economy and rising competitive pressures. Explanations for the divergence between productivity growth in the United States and the euro area since 1999 include different trends in employment, as well as differences in capital deepening (defined as the sum of the contributions from changes in the capital stock and changes in total hours worked) and in total factor productivity growth.
Looking at the sectoral breakdown (see Table 5), productivity growth for the euro area appears to correlate positively with exposure to international competitive pressures. Moreover, productivity growth in manufacturing remains considerably higher than in services, which in some cases have seen a negative growth rate over the most recent period.

Overall, the slowdown in labour productivity growth has been a common feature among all major euro area countries. However, the downward trend was particularly pronounced for Italy and Spain, where labour productivity growth (per person employed) was significantly below the euro area average for the same period. By contrast, the annual average change in labour productivity in Slovakia and Slovenia has been well above the euro area average.

Across the euro area, unit labour costs grew relatively quickly in most countries with the exception of Austria and Germany (see Chart 18). Compensation per employee has risen in all countries at well above the rate for labour productivity, albeit to different degrees. Whereas countries such as Slovenia and Slovakia show a marked discrepancy between

\begin{tabular}{|c|c|c|c|}
\hline \multicolumn{4}{|c|}{ (annual average over respective periods; percentages) } \\
\hline & 1980-1989 & 1990-1999 & 2000-2007 \\
\hline Total industries & 2.5 & 1.8 & 1.3 \\
\hline Agriculture, hunting, forestry and fishing & 6.1 & 5.5 & 1.6 \\
\hline Mining and quarrying & 1.0 & 4.7 & 2.0 \\
\hline Manufacturing of which & 3.2 & 2.6 & 2.9 \\
\hline Textiles, textile, leather and footwear & 2.7 & 2.5 & 2.1 \\
\hline Chemicals, rubber, plastics and fuel & 4.9 & 3.9 & 3.4 \\
\hline Machinery, nec & 2.9 & 1.7 & 2.6 \\
\hline Electrical and optical equipment & 4.7 & 3.9 & 6.4 \\
\hline Transport equipment & 3.9 & 2.6 & 3.0 \\
\hline Construction & 1.6 & -0.1 & -0.1 \\
\hline Wholesale and retail trade & 1.7 & 1.9 & 1.5 \\
\hline Transport, storage and communication & 3.2 & 4.1 & 2.7 \\
\hline Financial services & 1.3 & 1.9 & 3.5 \\
\hline Real estate, renting and business activities & -0.7 & -1.3 & -0.8 \\
\hline Community social and personal services & 0.7 & 0.4 & 0.4 \\
\hline
\end{tabular}

Source: Authors' calculations based on EU KLEMS.

Notes: The euro area corresponds to the EU KLEMS aggregate "Eurozone", which comprises all countries in the euro area as of 1 January 2001. 


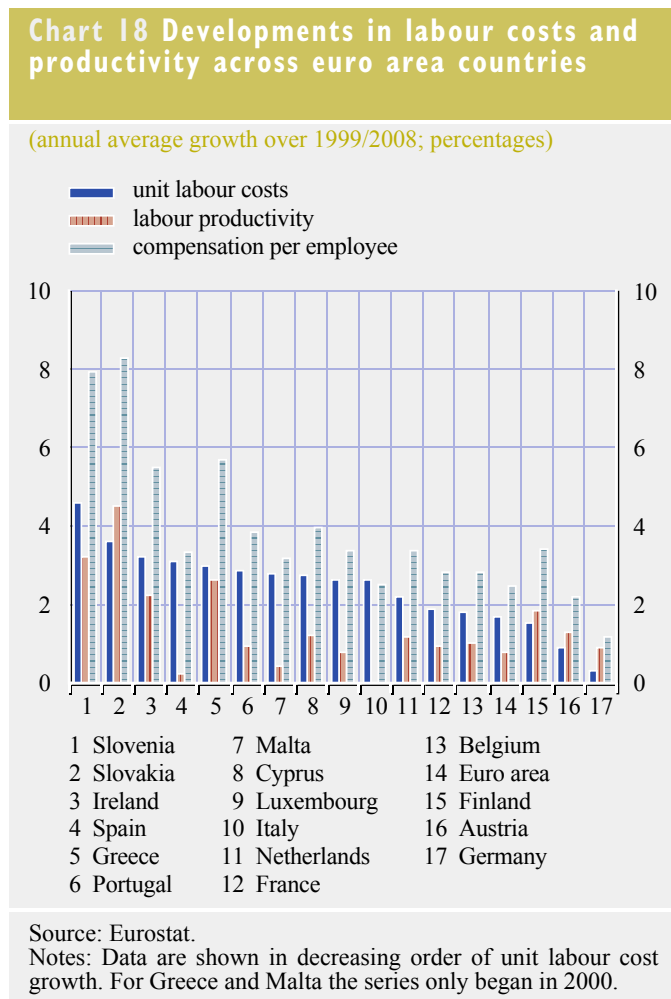

annual wage increases and annual productivity growth, in the case of Austria and Germany wage moderation has contributed to relatively muted growth in unit labour costs. This may be partly explained by differing growth momentum and the catching-up process in some of these economies. Existing market rigidity in some of the countries may also have played a role.

\section{EVIDENCE FROM BROAD-BASED COMPETITIVENESS MEASURES}

As mentioned in subsection 3.1 above, there are strong arguments to complement the competitiveness analysis based on traditional measures by adopting a more holistic approach. By shedding light on some of European firms' main drivers of productivity growth, the micro-founded framework - which combines information about firm-level productivity with macro fundamentals for the country is particularly useful when it comes to analysing the factors determining medium and long-term prospects for euro area competitiveness and related policy challenges.

\begin{tabular}{|c|c|c|}
\hline \multicolumn{3}{|c|}{ (based on data for 2003/05) } \\
\hline Countries & $\begin{array}{c}\text { Overall } \\
\text { competitiveness }\end{array}$ & $\begin{array}{c}\text { Producer } \\
\text { competitiveness }\end{array}$ \\
\hline Finland & 1 & 3 \\
\hline Belgium & 2 & 6 \\
\hline Netherlands & 3 & 1 \\
\hline Sweden & 4 & 2 \\
\hline Germany & 5 & 5 \\
\hline France & 6 & 9 \\
\hline Denmark & 7 & 4 \\
\hline Austria & 8 & 8 \\
\hline United Kingdom & 9 & 7 \\
\hline Italy & 10 & 11 \\
\hline Spain & 11 & 10 \\
\hline Portugal & 12 & 12 \\
\hline
\end{tabular}

Source: Authors' calculations.

Notes: In line with Ottaviano, Taglioni and di Mauro (2009), two types of competitiveness measure are shown: "overall" competitiveness and "producer" competitiveness. The former measures the actual competitive position of countries as determined by, among other factors, relative size, location and the level of barriers to imports and exports. Producer competitiveness captures the ability of countries to "generate" highly productive firms, regardless of market size and accessibility.

Looking at the situation prior to the crisis, the results of the calibrated model show that the most competitive (in accordance with the "overall competitiveness" indicator) countries are the ones centrally located (Belgium, the Netherlands) or combining technological superiority with easy market access (Finland, see Table 6 , column 1). ${ }^{15}$ These findings are in line with the theoretical model predicting that countries which are large or easily accessible to firms from trading partners should exhibit a tougher competitive environment and a greater capacity to channel resources from low-productivity to high-productivity uses. On the other hand, more peripheral countries such as the Mediterranean countries rank lower

15 While the methodological approach presented here represents a useful tool in understanding international competitiveness, there are some caveats arising from the important data limitations used in this type of analysis. In particular, currently available firm level data are not detailed and homogenous enough across European countries to allow for a consistent and fully-fledged econometric investigation. Hence, the above framework is estimated by means of a computable general equilibrium methodology that should be thought of as a second-best solution. As a consequence, a margin of error in the point estimates presented in Table 6 should be allowed, in particular for those countries whose firm-level data exhibit poorer coverage. Against this background, and given often small differences in scores across countries, country rankings should be treated with additional caution. 
because of a less central location in respect of their export markets and a possible technology disadvantage, which may also be a sign of high entry costs for foreign firms.

When geographical position is discounted and producer competitiveness focussed on instead (see Table 6, column 2), the Netherlands ranks first: it appears to have a strong technological advantage and a sound institutional environment conducive to the emergence and development of highly competitive firms. As the case of Sweden shows in particular, a peripheral location in itself does not represent a problem for a country, unless it is clearly compounded by relative technological and institutional disadvantages that hamper firm productivity. This contrasts with the Mediterranean countries, namely Spain, Italy and Portugal, which are consistently in the lower part of the competitiveness ranking, regardless of the yardstick used. This suggests the presence of parallel negative impacts from all the determinants of competitiveness identified in the model, i.e. geographical location, market access and technological and institutional (dis) advantage. At the same time, some centrally located countries, such as Belgium, show a rather sizable deterioration in terms of producer competitiveness compared to their ranking for overall competitiveness, denoting possible technology disadvantages and/or institutional bottlenecks that are partially offset by its central location.

Overall, the framework highlights once again that euro area firms had already been facing important challenges prior to the crisis that still call for appropriate policy measures. Pointing to the four key factors determining the global competitiveness of euro area countries - market accessibility, market size, technological advancement of the firms based in the country, and institutional structure - the framework calls for stronger market integration and competition at all levels, efforts to strengthen market flexibility, and the pursuit of further structural reforms to improve the allocation of resources, facilitate adjustment to globalisation-related structural changes and foster innovation. ${ }^{16}$

\subsection{IMPACT OF THE CRISIS ON EURO AREA COMPETITIVENESS}

The onset of the financial crisis and the ensuing decline in global economic activity and demand for traded goods and services had a strong impact on euro area exports, leading to increasing concerns about the euro area's competitiveness. While the severe downturn can partly be attributed to the relatively greater openness of the euro area, this has also raised the question of whether and to what extent the crisis has aggravated previous weaknesses. Although it may be too early to assess fully the medium-term impact of the crisis on competitiveness, the following section will make an initial attempt to examine the available evidence from standard indicators and present simulation results showing the impact of the crisis on broad-based competitiveness indicators, focussing mainly on the period from the deepening of the global economic and financial crisis and the global downturn in trade in 2008Q4 and 2009Q1.

\section{EVIDENCE FROM TRADITIONAL INDICATORS}

Along with the sharp contraction in export volumes, the euro area registered a further decline in export market shares (see Chart 11). While the unprecedented drop in global demand was the dominating factor behind the fall in euro area exports, other factors have also played a role. The fall in demand was particularly sharp for goods in which euro area exporters specialise. At the same time, the euro area also suffered from a deterioration in export price competitiveness. By contrast, the United States and the United Kingdom experienced improvements in price competitiveness over this period.

Among the euro area countries, Finland, Italy, Germany, Slovenia, Belgium, Portugal and Slovakia recorded losses in market shares compared to the pre-crisis levels reached at

16 For further details regarding policy implications, see di Mauro and Forster (2008).

\section{THE EURO AREA'S EXPORT PERFORMANCE AND COMPETITIVENESS: PRE-CRISIS TRENDS AND THE IMPACT OF THE FINANCIAL CRISIS}




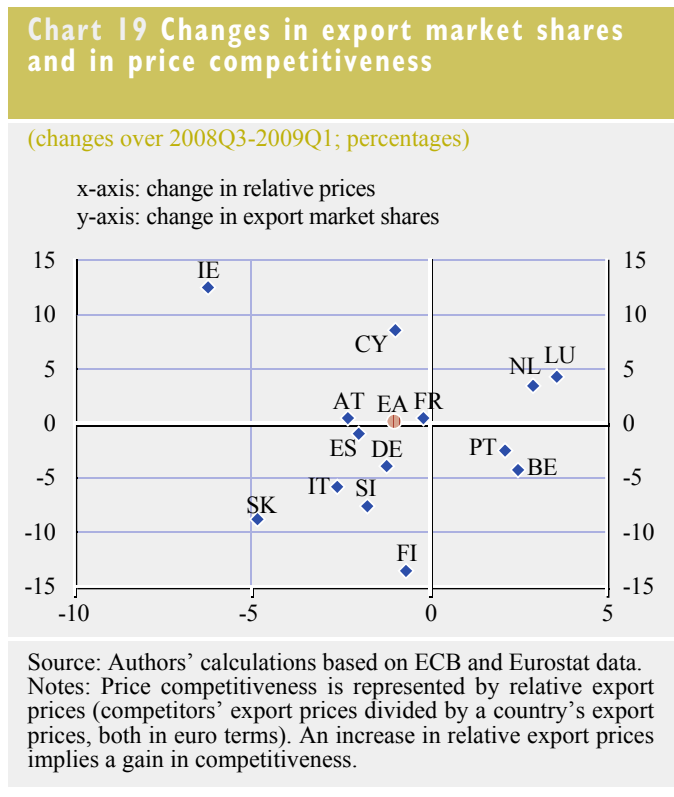

the end of 2008Q3 (see Chart 19). By contrast, Ireland, the Netherlands, Luxembourg and Cyprus saw gains in export market shares, with those of France, Austria and Spain being broadly unchanged. Looking at the interaction between export market shares and price competitiveness, the pre-crisis positive correlation seems to be

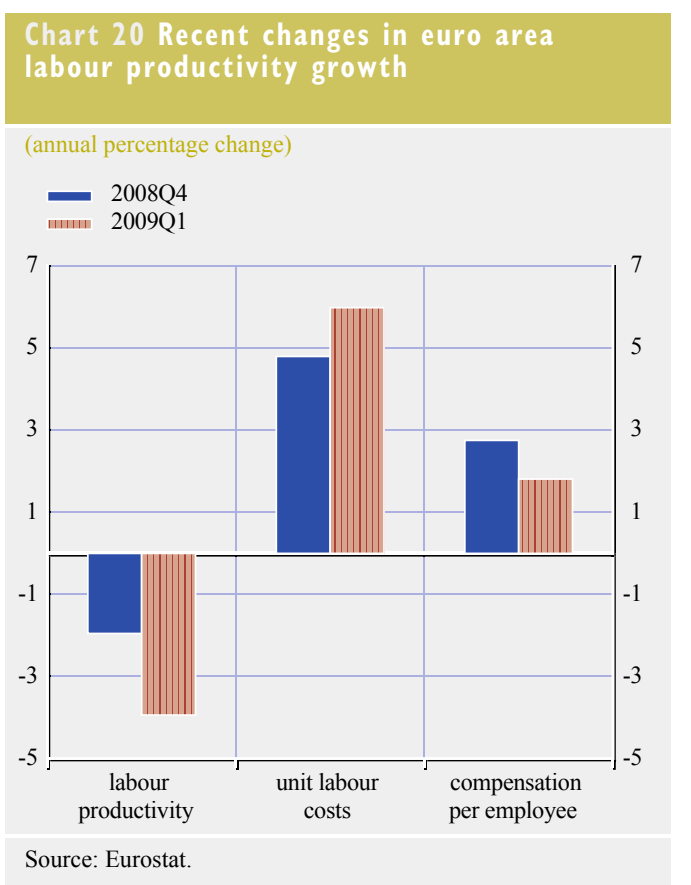

confirmed and actually reinforced for most of the euro area countries (see also Chart 19). It is noteworthy, however, that Germany - as late - has been among the countries to have recorded deteriorating price competitiveness and export market share losses, contrary to pre-crisis trends.

Relative developments in prices were also accompanied by significant changes in terms of productivity and unit labour cost developments. Recent Eurostat data show that labour productivity (by person employed) declined by about $2 \%$ in annual terms in the fourth quarter of 2008 , and by a further $4 \%$ in the first quarter of 2009 (see Chart 20). ${ }^{17}$ The decline in productivity growth was reflected in a substantial increase in unit labour costs over the same period, which grew at unprecedented rates in the period following the launch of EMU. Already showing a continued deceleration since the fourth quarter of 2006, the recent severe slowdown in productivity growth has been a somewhat unusual cyclical development. It chiefly reflects the fact that employment, in spite of the exceptionally large contraction in output experienced during the recent downturn, has remained resilient during the same period. This is partly explained by the high degree of employment protection for permanent workers and specific policy measures that allowed the intensified adoption of shorter working hours among employees. Across sectors, the decline in aggregate labour productivity was broadly driven by sectors that are typically more sensitive to changes in economic conditions (e.g. the industrial sector). However, it also signals an apparent reluctance of firms in these sectors to adjust the number of employees to current demand conditions. In comparison, US productivity growth also decelerated over the same period, but remained broadly positive. The substantial reduction in US employment following the slowdown in economic growth was reflected in a significant upturn in US productivity growth (per person employed).

17 If measured in terms of output per hour worked, productivity also declined, albeit at a slower pace. 
Despite the marked slowdown since mid-2008, US productivity growth has remained well above euro area productivity growth. ${ }^{18}$

The impact of the contraction in economic activity on euro area countries' labour markets was quite diverse, partly reflecting cross-country differences in the pattern of sectoral production and also in labour market institutions that affect the repartitioning of adjustment between employment and wages, between specific segments of the workforce and between employees working on different types of contracts. For instance, the extensive use of shorttime working arrangements, particularly by the industrial sectors in Germany and Italy, has impacted severely on productivity in these countries. On the other hand, lower reliance on such schemes in Spain and to a lesser extent in France, in combination with a greater reliance on traditional headcount adjustments, has yielded markedly different productivity patterns.
The impact of the shedding of a high proportion of workers on temporary contracts in Spain was even associated with accelerated productivity growth during the crisis period. ${ }^{19}$ By contrast, annual wage growth remained relatively high until the end of 2008, in spite of some deceleration. As most contracts are multi-annual and were concluded before the start of the contraction, this can partly explain the modest adjustment in wages seen during the period under review.

\section{BROADER MEASURES OF COMPETITIVENESS}

While firm-level data are not yet available for the crisis period, the micro-founded framework can also be used to simulate the effects of a global downturn. Starting from the benchmark

18 It is to be noted however that comparisons between the United States and the euro area are further complicated by the fact that the effects of the financial turmoil and the ensuing downturn were felt in the United States somewhat earlier than in the euro area.

19 For more details, see ECB Monthly Bulletin box, "Recent developments in euro area productivity", December 2009.

\section{Chart 2 I Simulation results of a decrease in global GDP and trade on overall competitiveness}

(percentage change relative to baseline overall competitiveness ranking)

a) by country

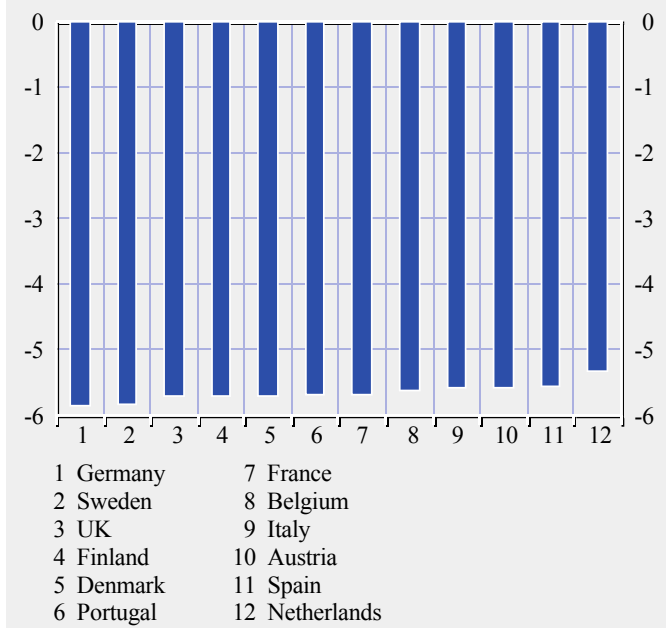

b) by sector

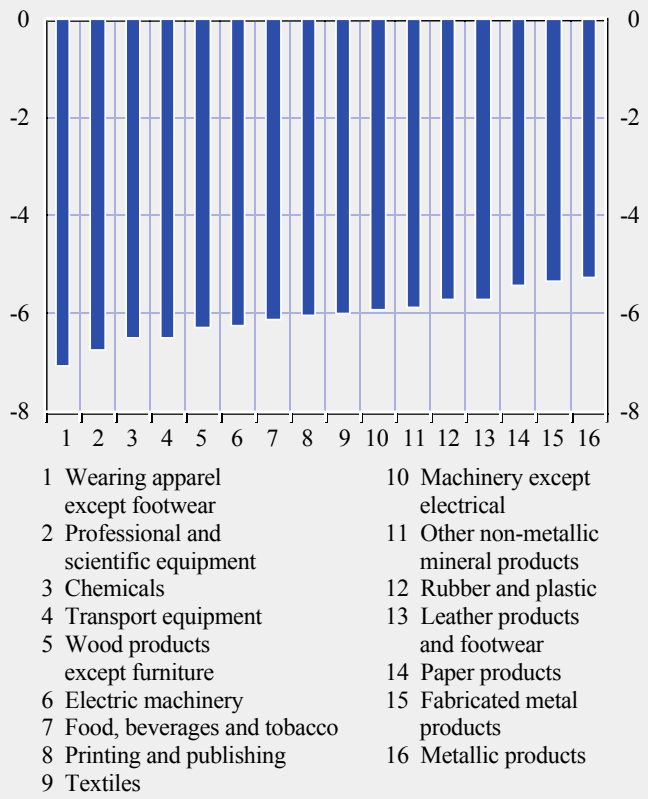


estimation and the measurement of overall competitiveness reported in Table 5, we can assess the impact of the global downturn on total factor productivity, and thus on the competitiveness of euro area firms in the medium and longer term, by looking at the changes in overall competitiveness. For that purpose, we simulate the combined impact of the actual decline in global GDP $(-2.5 \%)$ and trade $(-18 \%)$ in $2009 .{ }^{20}$ The results point to a generalised fall in overall competitiveness, i.e. a decrease in total factor productivity for all euro area countries (see Chart 21). Overall, there seem to be only slight differences in sensitivity to a generalised demand and trade shock, as the differences in the industrial structure of the countries under review are relatively small. Across sectors, differences in the overall impact on competitiveness are even more pronounced, with mostly intermediate production sectors having suffered the most, but primary and consumer production sectors the least.

\subsection{SUMMARY OF ASSESSMENT}

Euro area trade and competitiveness developments prior to the onset of the financial crisis were noticeably shaped by globalisation trends, in particular the integration of low-cost exporting economies into world trade. In the last decade, however, the losses in market share have been somewhat higher for the euro area than for other major competitors, indicating that unfavourable price competitiveness and other non-price competitiveness factors also played a role. In particular, the export specialisation of some euro area countries appears to have been a source of weakness. On the positive side, the euro area as a whole specialises in products with a medium to high technological content. These also benefited from the relatively strong growth in those sectors during the years prior to the crisis. Some countries, however, still mostly rely on exports of low-tech goods that tend to encounter less dynamic world demand, hampering gains in market share, and also more intense competition from low-cost countries.
As euro area exporters had been trying - with some difficulty - to adjust to the increasing challenges resulting from globalisation, the financial crisis came as a severe additional shock. None of the member countries were immune, the hardest hit being countries highly dependent on exports, particularly of intermediate and capital goods, most notably Germany and Finland. The fall in euro area exports - chiefly a reflection of the sharp decline in global demand - was amplified by adverse trends in price competitiveness amid a broadbased rise in the value of the euro. As a result, the euro area continued to lose export market shares over this period, in line with previous trends. Competitiveness also deteriorated in broader terms, as the exchange rate rise compounded a sharp and broad-based decrease in productivity. The latter mainly reflected the initially sluggish response in the employment sector owing to widespread government intervention. While the impact of the high exchange rate has proved to be only temporary, as the euro's value began to fall in late 2009, simulation results suggest that the crisis is nevertheless likely to continue to weigh on euro area competitiveness, owing to lower productivity growth in the longer term.

20 Technically, the simulation carried out assumes a joint reduction in two of the model's key parameters, namely market size and trade openness. 


\section{PROSPECTS FOR EURO AREA TRADE AND COMPETITIVENESS: WHAT HAVE WE LEARNED FROM THE RECOVERY SO FAR?}

Following the sharp downturn, we have recently witnessed a stronger than expected recovery in global trade flows. Euro area trade has also picked up, albeit at a slower pace than in other regions of the world. Against this background, this chapter will examine the ongoing recovery in global and euro area trade and discuss its broader implications for the trade and competitiveness outlook, also drawing on the micro-founded framework.

\section{I THE RECENT RECOVERY IN WORLD TRADE AND EURO AREA EXPORTS}

The recovery of global trade following the severe contraction of 2008/09 has been remarkable. The upturn that started to take hold in the second half of 2009 continued into 2010, with export growth in many countries well above the average over the last two decades. By mid-2010, international merchandise trade flows had almost fully recovered to the levels seen just before the collapse of Lehman Brothers (see Chart 22).

\section{Chart 22 Export volumes of goods by country group}

(volume indices: September 2008 $=100 ; 3$-month moving average)

world

..... advanced economies

=-1- emerging economies

- euro area

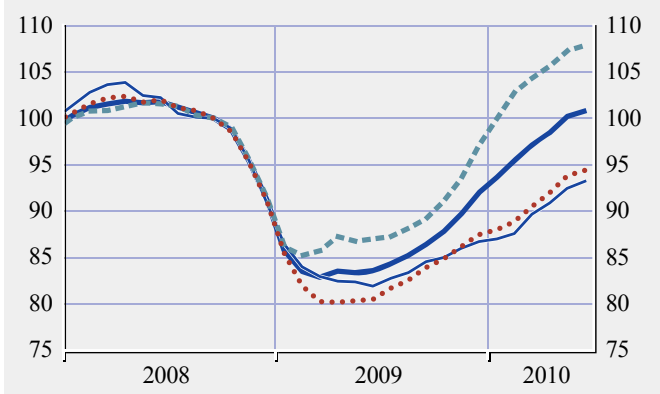

Source: Netherlands Bureau for Economic Policy Analysis (CPB).

Notes: Euro area exports correspond to both intra- and extra-euro area exports. The most recent observation refers to June 2010 .

While the downturn in 2008 and 2009 was highly synchronised, the recovery has so far shown some striking differences between the different countries/regions. The upturn in exports of emerging and developing countries has been more pronounced, partly due to the greater resilience of economic activity and the

\begin{tabular}{|c|c|c|c|c|}
\hline \multicolumn{5}{|c|}{ (percentage change; extra-euro area exports only) } \\
\hline & Peak & Trough & Peak to trough & Recovery since trough \\
\hline Austria & February 2008 & June 2009 & -27.7 & 19.1 \\
\hline Belgium & April 2008 & February 2009 & -26.3 & 29.4 \\
\hline Cyprus & February 2008 & June 2009 & -23.9 & 6.6 \\
\hline Finland & February 2008 & August 2009 & -39.4 & 16.8 \\
\hline France & February 2008 & March 2009 & -21.9 & 16.5 \\
\hline Germany & April 2008 & May 2009 & -29.9 & 31.0 \\
\hline Greece & June 2008 & November 2009 & -17.5 & 5.2 \\
\hline Ireland & August 2008 & August 2009 & -26.9 & 22.0 \\
\hline Italy & April 2008 & August 2009 & -35.6 & 29.0 \\
\hline Luxembourg & September 2008 & May 2009 & -28.1 & 13.2 \\
\hline Malta & January 2008 & December 2009 & -53.5 & -0.3 \\
\hline Netherlands & January 2008 & February 2009 & -22.2 & 16.4 \\
\hline Portugal & February 2008 & April 2009 & -24.5 & 12.3 \\
\hline Slovak Republic & February 2008 & February 2009 & -28.2 & 31.9 \\
\hline Slovenia & February 2008 & May 2009 & -34.2 & 17.8 \\
\hline Spain & September 2008 & January 2009 & -25.5 & 18.8 \\
\hline
\end{tabular}

Source: Eurostat.

Note: The most recent observation refers to June 2010. 
increased importance of intra-regional trade. In Emerging Asia, for instance, export levels had already reverted to their pre-crisis levels by the beginning of 2010. Nonetheless, in many countries, particularly advanced economies, the level of exports to date remains below its pre-crisis peak (see Chart 2 in Chapter II).

Euro area trade flows also picked up, but at a slower pace (see Table 7). Extra-euro area exports grew by almost $21 \%$ relative to its trough in May 2009, as opposed to a global upturn of around $24 \%$ and of approximately $20 \%$ in advanced economies. Although the euro area has benefited from the recovery in global demand (particularly from Asia), its strong trade links with emerging European and Commonwealth of Independent States (CIS) economies and the intermittent rise in the value of the euro seem to have stalled the recovery in euro area exports (see Chart 23). In addition, several euro area economies were hit particularly hard by the financial and property crises.

Among euro area countries the recovery has also been very patchy: while countries such as Slovakia and Germany were quicker to recover from their previous losses, others, like Malta, Greece and Cyprus, appear to have taken longer to bounce back from the global demand collapse. This divergence can also be partly explained by the composition of the recovery in demand, which has been more skewed towards intermediate goods (see also Chart 23) and demand from Asia.

With the trade recovery gathering pace, the question is whether this is likely to continue or whether the crisis will have a longerlasting impact. A closer look at the main factors behind the relatively strong recovery in trade may help shed some light on future developments.

The upturn in world trade was fuelled partly by some of the factors that had actually contributed to the collapse in trade in 2008/09. Firstly, the upswing in economic activity was mainly driven by the manufacturing sector, which is particularly trade-intensive, thereby boosting international trade flows. Secondly, world trade has also benefited strongly from the extraordinary policy interventions since the onset of the crisis, namely fiscal stimulus packages such as car-scrapping schemes, which also boosted demand for durable goods (particularly cars, which are

\section{Chart 23 Contributions to extra-euro area export growth}

(values; percentage points)

a) by geographical destination

- other countries

핀 non-EA member st.

- Asia

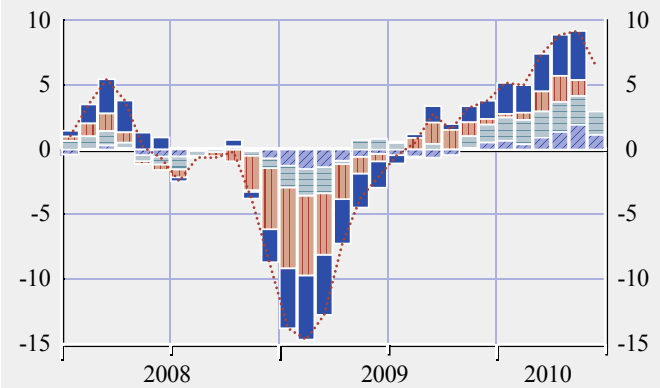

b) by type of goods

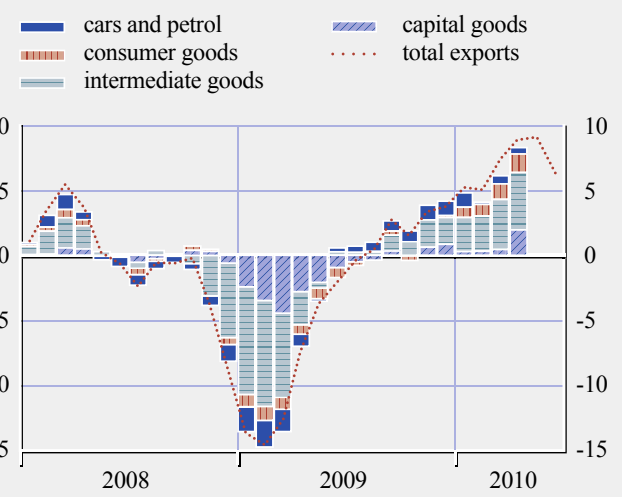

Source: Eurostat

Note: The most recent observation refers to April 2010, except for 'Total exports', 'Asia' and 'US' (June 2010). 
traded intensively). Thirdly, the upturn in the inventory cycle following the renewed growth of manufacturing activity and the likely gradual reactivation of global supply chains, combined with a normalisation of trade finance, have also contributed to the recovery.

The strength underlying the recent recovery in trade flows may indicate that at least part of the crisis's impact was temporary and did not cause severe long-term damage to trade and production processes. However, the short-lived nature of some of the support measures may induce some loss in trade momentum in the near term. Looking further ahead, the recovery in world trade will hinge significantly on the extent of the recovery in world demand and on its expenditure composition. Overall, global economic activity seems poised for a recovery at varying speeds across and within regions, with more robust growth in emerging countries compared to advanced ones. Furthermore, with the recovery in private demand expected to be somewhat sluggish in most advanced economies (hampered by possibly lasting impacts on financial sectors and household balance sheets), the resurgence of trade in these countries may be relatively slow in the medium term, possibly hindering the revival of world trade.

\section{THE "DECOUPLING" DEBATE AND THE INCREASING ROLE OF EMERGING ECONOMIES}

In this context, the pre-crisis "decoupling" debate, i.e. the extent to which emerging economies can make up for more sluggish growth in advanced countries, has resurfaced again. Without a doubt, emerging markets, particularly Asia, have gained prominence in global trade over the last decade, which is evident when we look at the rapidly increasing share in world exports and the export orientation of individual countries (see Chart 24). This was also accompanied by very strong growth in intra-regional trade, mainly as a result of changing trade patterns and the ongoing process of international production fragmentation ${ }^{21}$. In spite of this increase, recent empirical evidence has shown that advanced economies are still the main final destination markets for international trade activity. For

\section{Chart 24 Developments in Emerging Asia trade shares}

(12-month moving average)

- share of intra-trade in emerging Asia exports share of emerging Asia in world exports (right-hand scale)

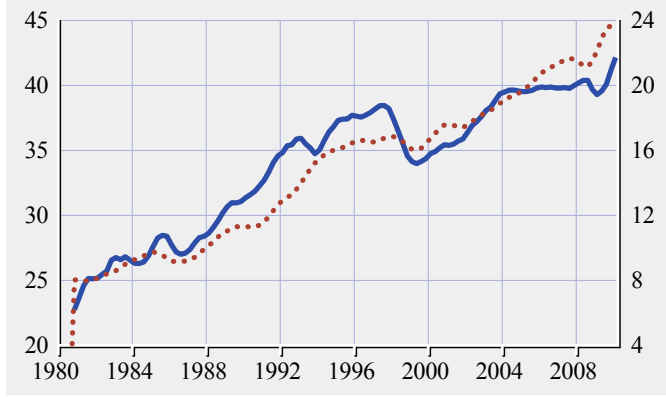

Source: Authors' calculations based on IMF data.

Note: The most recent observation refers to 2010Q1.

instance, Pula and Peltonen (2009) showed that in the case of Emerging Asia intra-regional demand only accounts for less that one-tenth of individual countries' value added, while more than a quarter of value added is generated from final demand originating outside the region, in particular from advanced economies.

Therefore, the medium-term outlook for world trade is likely to remain closely tied in with the future growth profile of advanced economies, more specifically the United States. Past recessions have shown that US business cycles and global economic developments tend to be closely linked ${ }^{22}$. In most cases, US-driven recessions have also been associated with downturns in world trade (see Chart 25), providing us with a useful benchmark for assessing current developments. Compared with previous recessions, particularly the recession in the early 1980s, the recent trade recovery seems to be relatively strong, although the depth of the

21 There are, however, some caveats to this analysis. The trade flow analysis based on the assumption of horizontal specialisation can be misleading about the nature and extent of trade integration among countries. A more meaningful analysis of trade patterns would require looking at data on parts and components instead of final (assembled) products.

22 For more information, see di Mauro et al. (2010). 


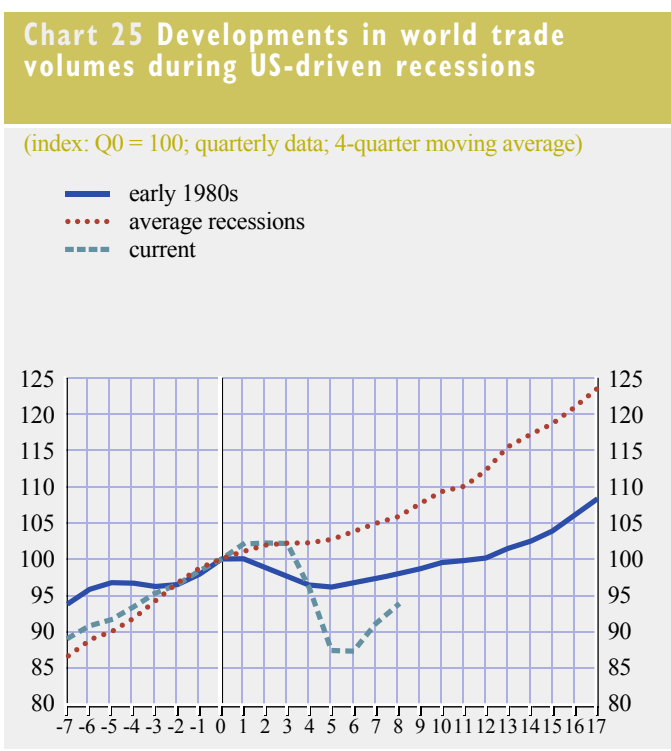

Sources: Authors' calculations based on IMF and ECB data. Note: Quarter "0" refers to the start of the US recession. Average based on US recessions since 1957.

current downturn in trade greatly exceeds that of previous recessions. This may be partly understood as a sign that the negative impact of the mechanisms behind the downturn in trade has been contained in relative terms.

\subsection{WHAT DOES THIS IMPLY FOR THE EURO AREA: MAIN CHALLENGES AND POLICY OPTIONS GOING FORWARD}

Although the euro area is set to benefit from the recovery in world demand, the outlook for euro area exports is expected to remain highly uncertain. Its strength and sustainability will also depend on how the euro area responds to both the challenges resulting from globalisation and new ones sparked by the recent downturn.

An important medium-term challenge for the euro area relates to the increasing role of emerging economies in world trade. With the recovery in world demand expected to be uneven, developments in euro area trade are likely to be strongly linked to the geographical and product composition of its export markets. If indeed emerging countries, particularly Asian economies, are expected to grow at a faster pace than advanced countries, the euro area as

\section{Chart 26 Composition of world imports and euro area foreign demand}
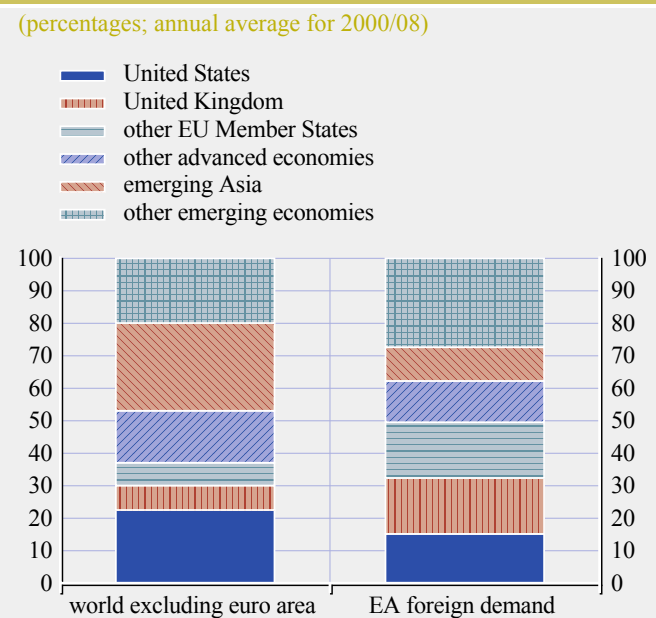

Source: Authors' calculations based on IMF data.

it currently stands may not be in a position to benefit fully from the present recovery in world demand. For instance, Emerging Asia currently represents about $27 \%$ of total world imports (excluding the euro area), but only about $11 \%$ of euro area foreign demand (see Chart 26). On the other hand, a more sluggish recovery in more traditional markets (such as other EU member states), which represent about $20 \%$ of euro area export markets, may hamper the recovery of exports in the euro area as a whole. The same logic applies among euro area member countries. In other words, the recovery in exports is also likely to vary across euro area countries, depending on their export market structure.

In this context, product composition also matters. For instance, particularly at the beginning of the recovery, imports in China recorded the strongest increases for primary goods and mineral fuels (of around $29 \%$ and $41 \%$ in the fourth quarter of 2009 compared to the previous quarter), showing China's big appetite for raw materials. However, imports in manufacturing and machinery, i.e. products and sectors in which euro area exporters specialise, grew far less, by around $14 \%$ over the same period. While euro area exports were buoyed in particular by 
higher demand for cars, the US may also have benefited from an increasing demand for iron and non-ferrous ores (accounting for some 7\% of US exports to China, see Chart 27).

The rise of the emerging economies may however be viewed not only as an important challenge for euro area exporters, but also as an opportunity for further expansion. More specifically, with a further expansion of production capacity in these economies, euro area exporters of machinery and equipment, who had shown signs of a strong competitive position prior to the crisis, may be set to benefit. In addition, greater private consumption and purchasing power in these countries as a result of rapid economic expansion may well lead to increased demand for consumption goods, particularly luxury goods, a traditional stronghold of euro area manufacturers.

Another important challenge for the euro area will be how to better address the need for European firms to restructure and strengthen their global competitiveness. Against the background of ongoing globalisation-related challenges, the outlook for euro area exports will also be highly dependent on the ability of European firms to pursue a restructuring process and to reverse some of the competitiveness losses witnessed before and during the crisis. Policies should therefore aim to rein in production costs as well as improve firms' productivity. In line with the micro-founded framework introduced earlier, this chiefly implies fostering technological innovation and higher human capital investment, and also facilitating necessary reallocations of resources over to more productive firms. Overall, a country's ability to adapt swiftly to external shocks depends on its ability to implement timely structural reforms in areas such as product and labour markets, innovation and research.

Moreover, given the key role of resource reallocation across firms and sectors and the fierce level of competition, as highlighted by the micro-founded framework, measures should aim to promote market integration and stronger competition at all levels. Tougher competition in local markets enhances local firms' productivity growth, allowing them to take better advantage of the increased accessibility to foreign markets, and this will ultimately

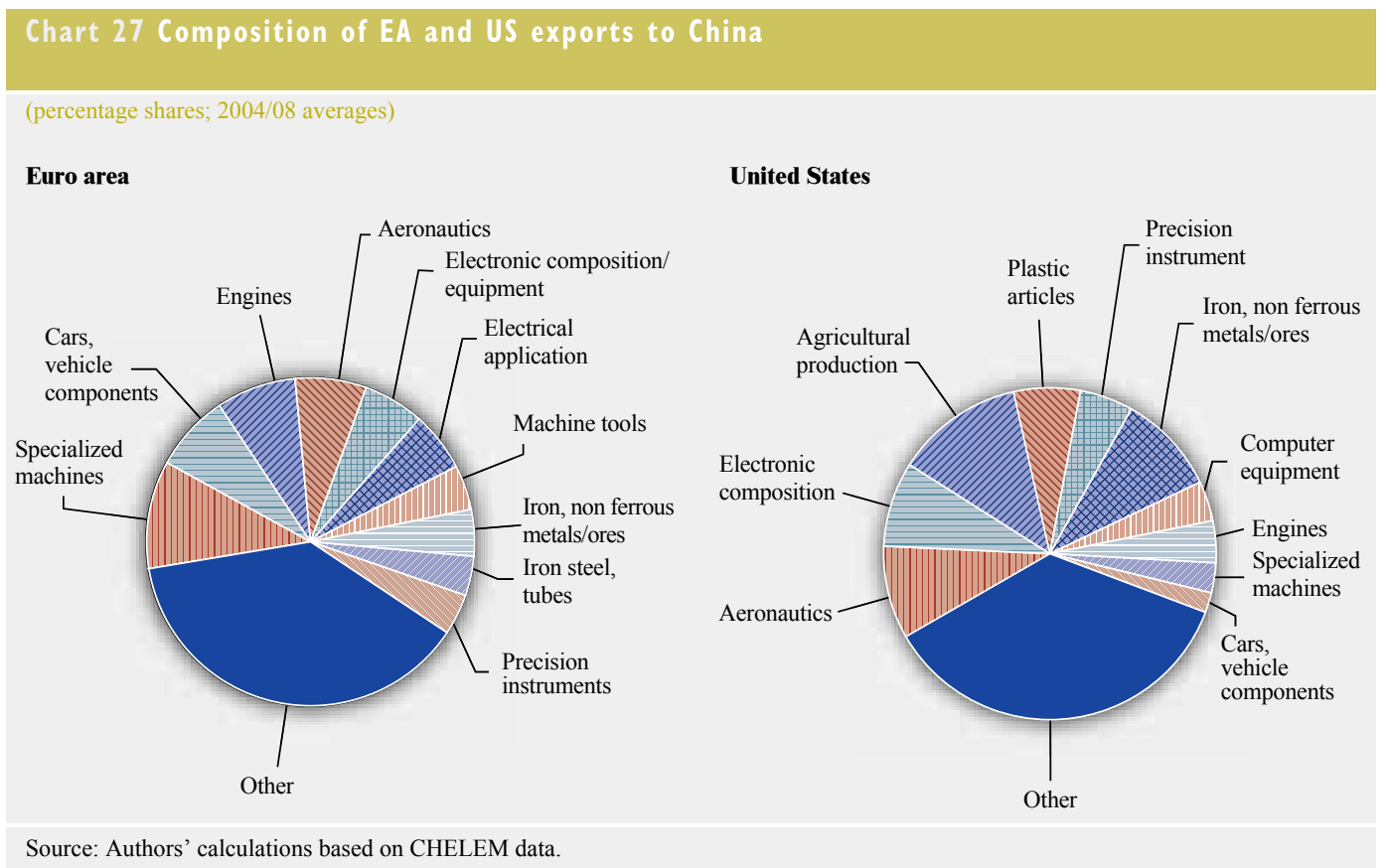


result in better export performance on the part of the euro area countries. Furthermore, larger local markets are generally more attractive for foreign competitors, whose entry into them will increase competition further and foster higher productivity growth. Consequently, continuing and strengthening the process of market integration within Europe through EU policies on the single market appears to be an important tool for supporting and strengthening the global competitiveness of European firms.

On the other side of the spectrum, a possible rise in protectionist policies could seriously hamper the recovery in trade ${ }^{23}$. Since the outbreak of the financial crisis, a number of protectionist measures have been implemented around the world, but their economic impact appears to be relatively contained so far (Bussière et al., 2010). However, the different macroeconomic outlook ahead may lead to a further rise in public calls for the implementation of protectionist measures. Nonetheless, a resurgence in trade protectionism would significantly impair the still brittle recovery process by further undermining already fragile trade flows and global demand.

Model simulations based on the micro-based framework broadly confirm this assessment. They clearly show that a rise in protectionism would lead to a worldwide loss in efficiency and firms' productivity and thus to losses in competitiveness. Chart 28 shows the results for a counterfactual scenario where access to trade is reduced worldwide by $5 \%$. The simulation is carried out by recalculating bilateral and sectoral trade frictions and then using these to calculate the inferred change in overall competitiveness. The results can be interpreted as follows: if all fifteen OECD countries in the sample raised their barriers to imports from abroad in a hypothetical trade war, the loss in productivity across countries would be substantial. As expected, in terms of international competitiveness all countries would lose out to some extent. This is due to the fact that greater protectionism induces firms to cut back on their average scale of operations. This in turn leads to a less efficient productive environment, higher average prices

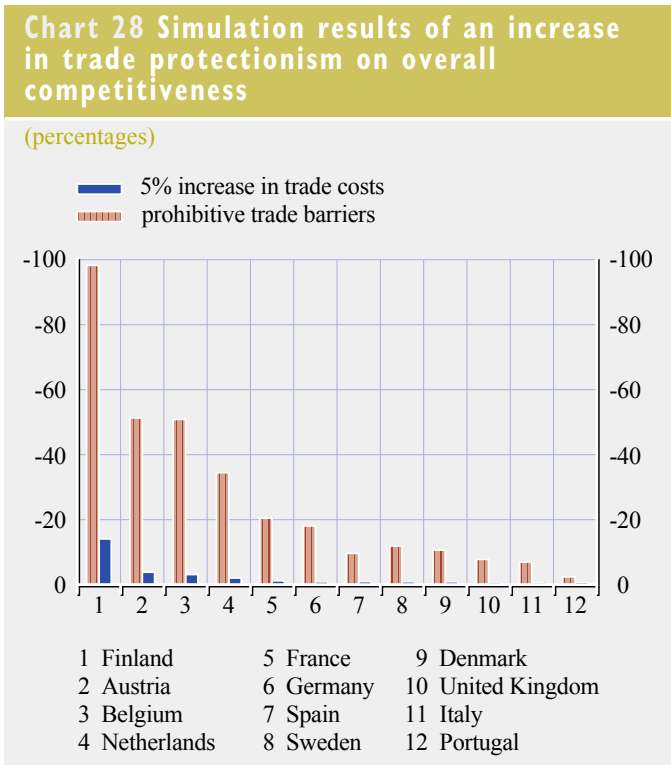

Source: Authors' calculations based on Ottaviano et al. (2009). Notes: Percentage changes relative to the baseline overall competitiveness ranking; a minus sign denotes a loss in overall competitiveness.

for consumers and higher mark-ups. However, the expected losses would be bigger for the smaller and more competitive countries (most notably Belgium, Finland and Austria). In comparison, losses for relatively disadvantaged countries - either because of a poor level of producer competitiveness (Portugal) or because of geographical remoteness - would be on a relatively small scale, primarily due to an already poor performance prior to the move towards protectionism. At the same time, countries that benefit from a large domestic market, such as Germany, would also be likely to be less affected by an increase in trade protectionism.

23 The negative consequences of a rise in protectionism have been widely discussed in economic literature. More generally, trade protectionism imposes substantial direct welfare costs on consumers (because tariffs raise prices) and taxpayers (given that subsidies are associated with higher taxes). It also reduces efficiency in the use and allocation of resources within the economy (under protectionism, domestic producers can specialise in goods and services in which they are not competitive or do not have a comparative advantage). Furthermore, protectionism may result in lower productivity growth rates, providing fewer incentives to adopt new technologies, with negative implications for real GDP growth and competitiveness in the longer run. The Great Depression in particular showed how intensifying protectionist measures can delay the recovery in world trade and aggravate the length and extent of the downturn. 
The reason for such a smaller impact is that a large home market allows resources to be allocated efficiently within domestic borders despite the decrease in foreign competition.

In order to provide a benchmark for the gains/ losses resulting from a $5 \%$ increase in trade barriers, Chart 28 also shows ranges resulting from a comparison of the effects of imposing prohibitive trade barriers, i.e. barriers that prevent any trade, in all sample countries. The additional loss in overall competitiveness ranges from $2 \mathrm{pp}$ (Portugal) to more than $80 \mathrm{pp}$ (Finland). This indicates that the effect of protectionism on countries' overall competitiveness, while being consistently negative, is non-linear. A combination of domestic and international factors contributes to determining its impact.

In conclusion, protectionism leads to a worldwide loss in efficiency and firms' productivity. It does so by reducing the average scale of firms. This in turn leads to higher average prices for consumers and higher mark-ups. These effects are more pronounced for smaller and/or more open countries. They are also more severe for countries specialised in sectors more open to trade, and thus more susceptible to firm selection, and for those whose firms are highly competitive on average. 
Against the backdrop of a changing global environment and the globalisation of production processes, the unprecedented decline in world trade in 2008/09 has raised some concerns and questions regarding the external performance of the euro area and its ability to compete in the global market place. Based on a varied number of indicators, this Occasional Paper has analysed the export and competitiveness performance of euro area exporters during the recent economic and financial crisis, comparing this with previous trends and evaluating its possible impact on prospects going forward.

World trade flows collapsed following the deepening of the financial crisis in September 2008, triggered mainly by a global decline in demand for traded goods. The response of trade to the fall in global activity was particularly striking, indicating that the responsiveness of trade to movements in income had changed significantly. The nature of the global demand shock, the increased role of global production chains, and problems affecting access to trade finance, are some of the factors identified as having possibly magnified and further propagated the global demand shock.

Although the reach of the global financial crisis and recession was widespread, the impact was particularly severe in the euro area. The decline in global demand for European goods had a dramatic impact on export flows, aggravated somewhat by unfavourable developments in price competitiveness. As a result, the euro area lost further export market shares over this period, in line with previous trends. Simulation results based on a more holistic approach to competitiveness show that European countries also suffered substantial losses in (total factor) productivity, which will also weigh upon the global competitiveness of euro area firms in the medium and longer terms.

Looking ahead, the outlook for world trade will be subject to an unusually high degree of uncertainty, particularly in a context of possibly changing relationships between trade and final demand. Moreover, the prospects for trade will be closely linked to the recovery of global demand and its expenditure composition. Assuming that the impact of the factors behind the downturn in trade was merely temporary and that there has been no permanent change in previous globalisation trends, it is likely that trade flows will recover in line with a recovery in final demand. In general, it may be too early as yet to assess the full impact of the crisis in world trade. Data limitations in particular make it harder to assess the true nature and contribution of the factors behind the downturn. Nevertheless, the stronger than expected recovery in world trade following the downturn may suggest that some of the factors behind the downturn in trade were mainly of a temporary nature and that previous globalisation trends are likely to remain in place.

In terms of the euro area, as the recovery in world demand is expected to be uneven (and driven mainly by emerging economies) the performance of the external sector may be hindered by the geographical orientation of the euro area's export markets, which are mainly focused on advanced economies and other EU member states. Furthermore, the strength and sustainability of the recovery in exports will also be dependent on the restructuring process undertaken by European firms in response to ongoing globalisation challenges. This implies that the significant divergences in terms of current account balances and price competitiveness within and outside the euro area, which were brought into particularly sharp focus by the global downturn and the recent European sovereign debt crisis, will need to be addressed urgently. To assess the medium and long-term prospects for euro area competitiveness, we have presented results from a model-based framework which allows countries to be ranked in terms of their productivity. Such a framework points yet again to a pressing need to implement further structural reforms in the euro area in order to facilitate a fast and smooth reallocation of both firms and their workforce - from lagging 
to more advanced and promising industries, or from lower to higher-productivity firms - and to further enhance aggregate productivity growth. By contrast, we have seen that a resurgence in protectionist policies could seriously dampen the outlook for euro area exports and should be strongly resisted.

Overall, the policy response to the challenges in terms of competitiveness for the euro area as a whole and the related differences between member countries should rest on three pillars, namely (i) higher productivity growth and innovative activity in the entire economy and the restoration of price competitiveness (ii) structural reforms, and (iii) openness to trade. First, all euro area economies should intensify their efforts to foster productivity growth and innovation in the entire economy. Rather than hurting other member countries, raising aggregate productivity growth in the individual countries will also have positive spillover effects, as it helps to ensure high living standards and also the global competitiveness of the euro area as a whole in the longer term. On the other hand, social partners in countries with lower competitiveness should facilitate the adjustment by containing wage increases below productivity gains. Second, all member countries should continue to implement structural reforms aimed at producing more flexible goods and labour markets, including a healthy process of selection, which would potentially allow only the most productive firms to operate. At the same time, strengthening market integration within Europe will create larger local markets that are more attractive for foreign competitors, whose market entry would again increase competition and foster firm productivity growth. Greater flexibility would also allow for a smoother labour force adjustment across sectors, respectively in line with productivity. Third, all euro area economies would benefit from embracing openness to international trade, including imports. This also implies that governments should resist potential protectionist pressures that may intensify amid weak labour markets and the lack of fiscal leeway. 


\section{ANNEXES}

I PRICE COMPETITIVENESS AND EURO AREA

COUNTRIES - ADDITIONAL INFORMATION

\section{Chart 29 Export market shares and competitiveness across euro area countries}

(index: 1999 Q1=100; quarterly data; seasonally adjusted)

\section{Export market shares}

- euro area

.... Germany

$=$ Spain

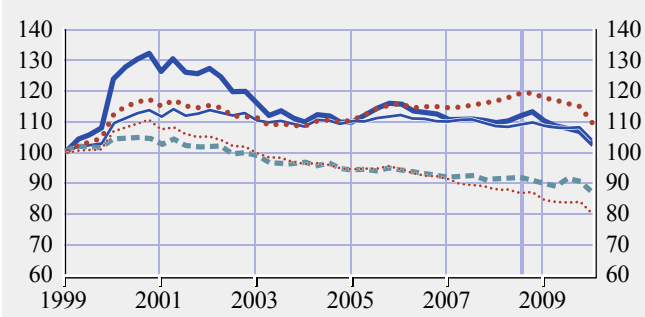

Ireland

-.... Luxembourg

$== \pm$ Austria

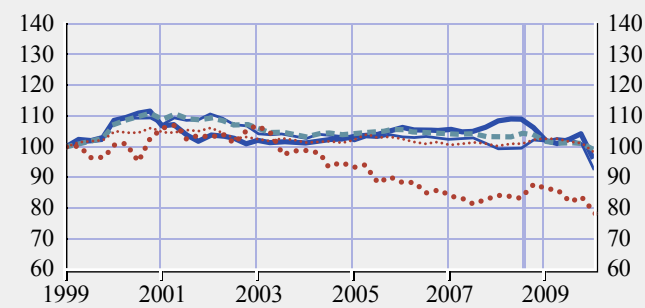

\section{- Finland =-=- Cyprus}

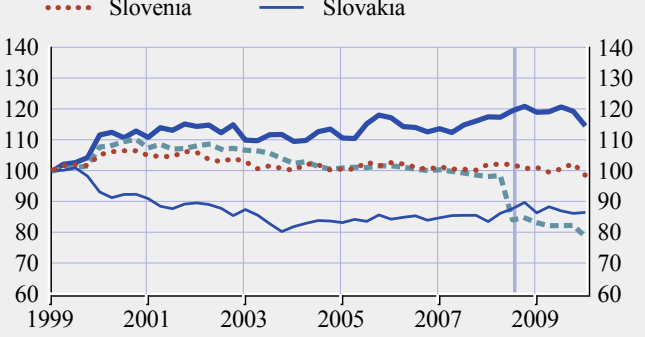

Sources: Eurostat national accounts and ECB.

Note: The most recent observation refers to $2010 \mathrm{Q} 1$.

\section{Relative export prices}
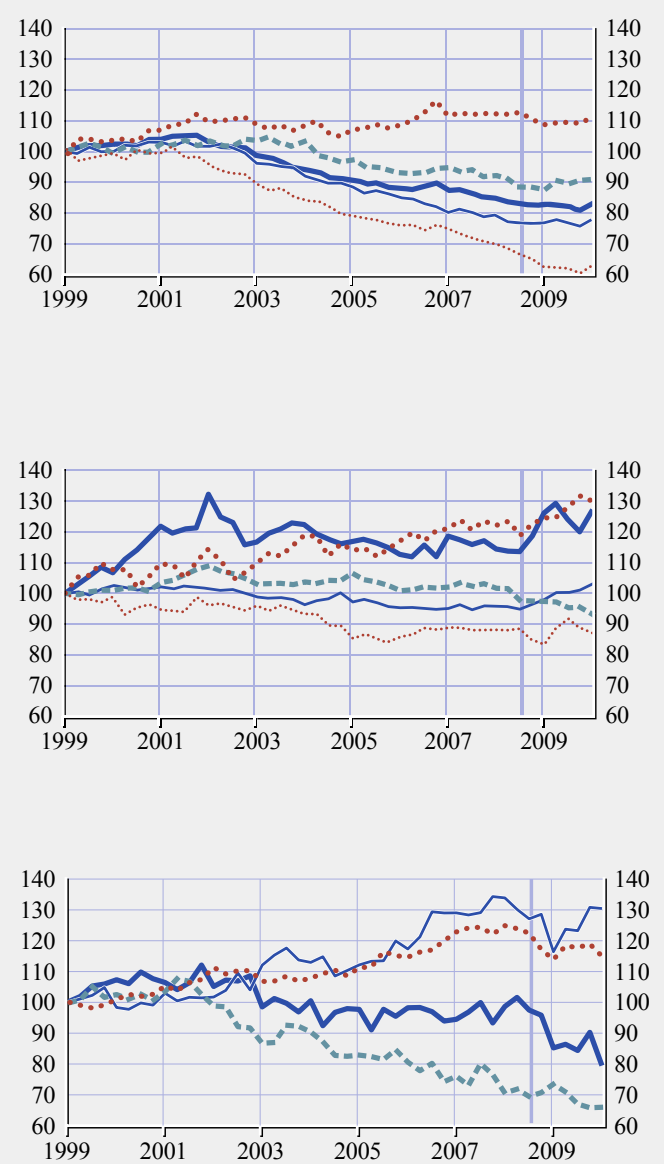


\begin{tabular}{|c|c|c|c|c|c|c|c|c|c|c|c|c|}
\hline \multicolumn{13}{|l|}{ (average 2005/08; based on values in USD) } \\
\hline & $\begin{array}{r}\text { EA (intra + } \\
\text { extra) }\end{array}$ & $\begin{array}{r}\text { of which } \\
\text { B/LUX }\end{array}$ & $\mathrm{DE}$ & IR & GR & ES & FR & IT & $\mathbf{A U}$ & NL & PT & FI \\
\hline \multicolumn{13}{|l|}{ Memo item: } \\
\hline Share in total world exports & 33.7 & 3.6 & 11.4 & 1.1 & 0.2 & 2.1 & 4.7 & 4.2 & 1.3 & 3.5 & 0.4 & 0.8 \\
\hline High-technology industries (HT) & 0.8 & 0.7 & 0.8 & 2.1 & 0.5 & 0.4 & 1.0 & 0.4 & 0.5 & 1.2 & 0.5 & 1.0 \\
\hline Aircraft and spacecraft & 1.0 & 0.2 & 0.8 & 0.2 & 0.4 & 0.6 & 3.8 & 0.4 & 0.4 & 0.2 & 0.3 & 0.1 \\
\hline Pharmaceuticals & 1.6 & 2.8 & 1.4 & 6.3 & 2.1 & 1.3 & 1.8 & 1.1 & 1.3 & 1.0 & 0.3 & 0.5 \\
\hline $\begin{array}{l}\text { Office, accounting and computing } \\
\text { machinery }\end{array}$ & 0.7 & 0.4 & 0.6 & 3.1 & 0.1 & 0.1 & 0.4 & 0.1 & 0.2 & 2.3 & 0.4 & 0.2 \\
\hline $\begin{array}{l}\text { Electronics and communications } \\
\text { equipment }\end{array}$ & 0.5 & & & & 03 & 03 & & 02 & 04 & 00 & 0 & 19 \\
\hline Medical, precision and optical instruments & 0.9 & 0.2 & $\begin{array}{l}0.5 \\
1.2\end{array}$ & $\begin{array}{l}0.7 \\
1.3\end{array}$ & $\begin{array}{l}0.3 \\
0.3\end{array}$ & $\begin{array}{l}0.3 \\
0.3\end{array}$ & $\begin{array}{l}0.9 \\
0.9\end{array}$ & $\begin{array}{l}0.2 \\
0.7\end{array}$ & $\begin{array}{l}0.4 \\
0.7\end{array}$ & $\begin{array}{l}0.9 \\
1.2\end{array}$ & $\begin{array}{l}0.7 \\
0.2\end{array}$ & $\begin{array}{l}1.9 \\
0.8\end{array}$ \\
\hline $\begin{array}{l}\text { Medium/high-technology industries } \\
\text { (MHT) }\end{array}$ & 1.2 & 1.0 & 1.4 & 0.9 & 0.5 & 1.3 & 1.1 & 1.3 & 1.2 & 0.8 & 0.9 & 0.9 \\
\hline Electrical machinery and apparatus & 0.9 & 0.5 & 1.1 & 0.3 & 0.7 & 0.8 & 0.9 & 0.8 & 1.2 & 0.5 & 0.9 & 1.1 \\
\hline $\begin{array}{l}\text { Motor vehicles, railway and transport } \\
\text { equipment }\end{array}$ & 1.3 & 1.2 & 1.7 & 0.0 & 0.1 & 2.2 & 1.3 & 0.8 & 1.2 & 0.4 & 1.2 & 0.5 \\
\hline Chemicals excluding pharmaceuticals & 1.2 & 1.9 & 0.9 & 4.1 & 0.7 & 0.9 & 1.3 & 0.7 & 0.4 & 1.6 & 0.6 & 0.7 \\
\hline machinery and equipment, (n.e.s.) & 1.2 & 0.7 & 1.5 & 0.2 & 0.5 & 0.8 & 1.0 & 2.1 & 1.7 & 0.7 & 0.7 & 1.2 \\
\hline $\begin{array}{l}\text { Medium/low-technology industries } \\
\text { (MLT) }\end{array}$ & 0.9 & 1.4 & 0.8 & 0.2 & 1.6 & 1.1 & 0.8 & 1.0 & 1.0 & 0.9 & 1.0 & 1.2 \\
\hline Building and repairing of ships and boats & 0.6 & 0.1 & 0.4 & 0.0 & 1.4 & 1.7 & 0.6 & 1.3 & 0.1 & 0.6 & 0.5 & 1.9 \\
\hline Rubber and plastics products & 1.2 & 2.2 & 1.2 & 0.2 & 1.3 & 1.2 & 1.1 & 1.1 & 1.0 & 1.3 & 1.1 & 0.7 \\
\hline Other non-metallic mineral products & 1.1 & 1.2 & 0.9 & 0.3 & 2.8 & 2.2 & 1.0 & 2.0 & 1.4 & 0.6 & 2.8 & 0.9 \\
\hline Basic metals and fabricated metal products & 0.8 & 1.1 & 0.7 & 0.1 & 1.7 & 0.8 & 0.7 & 0.8 & 1.1 & 0.7 & 0.7 & 1.3 \\
\hline Low-technology industries (LT) & 1.0 & 1.0 & 0.8 & 0.7 & 1.7 & 1.1 & 0.9 & 1.1 & 1.0 & 1.2 & 1.5 & 1.0 \\
\hline Wood, pulp, paper and paper products & 1.2 & 1.1 & 1.1 & 0.2 & 0.7 & 1.2 & 1.1 & 0.9 & 2.2 & 0.9 & 2.3 & 6.6 \\
\hline Agriculture, food, beverages and tobacco & 1.0 & 1.0 & 0.6 & 1.1 & 3.0 & 1.7 & 1.3 & 0.8 & 0.9 & 2.0 & 1.1 & 0.6 \\
\hline Textiles, clothing and footwear & 0.8 & 0.9 & 0.5 & 0.1 & 2.1 & 1.0 & 0.7 & 2.0 & 0.6 & 0.5 & 2.4 & 0.2 \\
\hline Not elsewhere specified products (n.e.s.) & 0.9 & 1.0 & 1.1 & 0.9 & 0.5 & 0.5 & 0.6 & 0.9 & 1.1 & 1.0 & 1.2 & 0.5 \\
\hline
\end{tabular}

Sources: CHELEM database and ECB calculations.

Notes: Euro area exports include intra-euro area trade. Total exports exclude exports of energy-related products.

\section{Table 9 Definition of country groups}

\section{Country/region}

Euro area

United Kingdom

United States

Japan

China

Other emerging Asia

CEECs

\section{Countries included}

16 euro area member countries; excludes intra-euro area trade flows, unless stated otherwise United Kingdom

United States

Japan

China

India, Indonesia, Hong Kong, Singapore, South Korea, Taiwan, Malaysia, Philippines, Thailand CIS (Armenia, Azerbaijan, Belarus, Georgia, Kazakhstan, Kyrgyzstan, Republic of Moldova, Russian Federation, Tajikistan, Turkmenistan, Ukraine, Uzbekistan), Estonia, Lithuania, Latvia, Former Yugoslavia (then Bosnia and Herzegovina, Croatia, Macedonia, Serbia, Montenegro), Albania, Bulgaria, Former Czechoslovakia (then Czech Republic and Slovakia), Hungary, Poland, Romania, Turkey. 


\section{Table 10 Product classification by technological intensity}

High-technology industries (HT)

Aircraft and spacecraft

Pharmaceuticals

Office, accounting and computing machinery

Electronics and communications equipment

Medical, precision and optical instruments

Medium/high-technology industries (MHT)

Electrical machinery and apparatus, (n.e.s.)

Motor vehicles, trailers and semi-trailers, railway and transport equipment, (n.e.s.)

Chemicals excluding pharmaceuticals

Machinery and equipment, (n.e.s.)

Medium/low-technology industries (MLT)

Building and repairing of ships and boats

Rubber and plastics products

Other non-metallic mineral products (including mining and quarrying)

Basic metals and fabricated metal products (including mining and quarrying)

Low-technology industries (LT)

Wood, pulp, paper, paper products, printing and publishing

Agriculture, fishing and food products, beverages and tobacco

Textiles, textile products, leather and footwear

Manufacturing of furniture, toys, not elsewhere specified products (n.e.s.)

Source: Based on the OECD's Science, Technology and Industry Scoreboard (2005), page 181-183. 
Predominantly raw material-intensive

\section{Fertilisers}

Iron ores

Non-ferrous ores

Unprocessed minerals (n.e.s.)

Coals

Crude oil

Natural gas

Coke

Refined petroleum products

Cereals

Other edible agricultural production

Non-edible agricultural production

Cereal products

Fats

Meat

Preserved meat/fish

Preserved fruits

Sugar

Animal food

Predominantly labour-intensive

Cement

Ceramics

Glass

Yarns and fabrics

Clothing

Knitwear

Carpets

Leather

Wood articles

Furniture

Paper

Printing

Miscellaneous manufactured items

Metallic structures

Miscellaneous hardware

Arms

Plastics

Jewellery, works of art
Predominantly capital-intensive

Iron and steel

Tubes

Non-ferrous metals

Vehicle components

Cars and cycles

Commercial vehicles

Paints

Toiletries

Rubber articles (include tyres)

Electricity

Beverages

Manufactured tobaccos

Predominantly research-intensive

Consumer electronics

Telecommunications equipment

Computer equipment

Basic inorganic chemicals

Basic organic chemicals

Pharmaceuticals

Plastic articles

Engines

Agricultural equipment

Machine tools

Construction equipment

Specialised machines

Precision instruments

Clockmaking

Optics

Electronic components

Domestic electrical appliances

Electrical equipment

Electrical apparatus

Ships

Aeronautics

Not classified

Non-monetary gold

N.e.s. products

Sources: Based on Yilmaz (2003) and slightly amended by authors. 


\section{OVERVIEW ON THE METHOD USED TO QUANTIFY OVERALL AND PRODUCER COMPETITIVENESS}

In line with Ottaviano, Taglioni and di Mauro (2009), we calibrate a general-equilibrium, multi-country, multi-sector model of international trade, with firms that differ in terms of their productivity. With a view to reproducing as realistic a pattern as possible, the model also features differentiated goods, monopolistic competition and variable mark-ups. Countries served by a large number of domestic and foreign firms end up generating more productive, internationally competitive firms and post, on average, lower mark-ups, lower prices and, ultimately, higher welfare levels.

The parameters of the theoretical model are calibrated using industry-level bilateral trade data and firm-level productivity data. With the aim of openly connecting the model to empirical projections, we take the following steps:

1. We estimate trade frictions using the "gravity equation" method, thereby inferring from trade flows the obstacles that hamper trade among the countries analysed.

2. We estimate total factor productivity (TFP) at the firm level ("firm competitiveness") and derive the resulting distributions of firms' productivity across countries and sectors.
3. The above estimates, based on theoretical derivations, are complemented by data on country size (population and GDP) and average sectoral labour productivity to generate two competitiveness indices for each country: an index of overall competitiveness, and one of producer competitiveness. The first index is aimed at reflecting, as realistically as possible, the actual competitive position of countries. The second index disregards countries' differences in terms of size and trade frictions as well as other international factors to focus instead on a country's technological and institutional determinants of competitiveness. In so doing, it assesses the ability of a country to generate more productive firms in a hypothetical world without geographical and country size differences.

4. Furthermore, by retaining countries' producer competitiveness as a given, the calibrated model can also be used to simulate policy changes, such as changes in free trade or trade frictions associated with an increase in market accessibility (as an illustration, see also Box 1), transport costs, the level of linguistic-cultural barriers, the level of technical barriers to trade, size of home market and the degree of concentration in the cost distribution of firms (or impacts of productivity shocks in specific sectors). Tables A3.1 and A3.2 report the results for all possible counterfactual scenarios, using a $10 \%$ variation in the relevant parameter.

\section{Box $\mid$}

MECHANISMS OF FIRMS' ADJUSTMENTS TO A CHANGE IN TRADE BARRIERS

(FOLLOWING BUSSIÈRE ET AL., 20I0)

Government actions that result in a build-up of barriers to international trade imply lower profit expectations for firms as they are forced to scale back their operations. The aggregate outcome for the economy is portrayed in the graph, where we assume that both the domestic country and its foreign counterparts reduce foreign firms' access to the respective domestic market. This situation is realistic as countries usually retaliate against foreign commercial policies which they deem aggressive. 
In order to follow the mechanisms of firms' adjustments to a change in trade barriers, the key parameter to use is 'domestic cut-off'. The cut-off is an inverse number of the minimum productivity that a firm needs to survive in a given market. It is also a determinant of overall competitiveness and inversely correlated to it.

Hence, at a given level of domestic cut-off $\mathrm{c}_{\mathrm{s}}^{\mathrm{hh}}$, the effect of a "multilateral" protectionist move is shown graphically by the downward shift of the expected profit curve and the corresponding shift to the right of the point of intersection between the curves depicting expected profits and entry costs respectively. As the graph shows, the new equilibrium domestic cut-off $\mathrm{c}_{\mathrm{s}}^{\text {hh }}$ will be higher, i.e. firms on average will become less productive.

\section{Industry reallocations following a multilateral move towards protectionism}

$\mathrm{x}$-axis: cut-off cost

y-axis: expected profits /entry costs

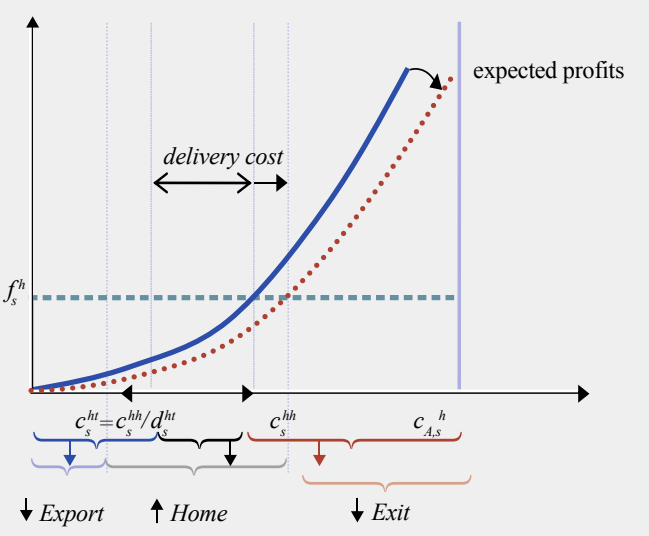

Source: Ottaviano et al. (2009).

This outcome is due to the following sequence of events: lower expected profits result in some foreign firms exiting the domestic market. This has the immediate effect of easing some of the competition from imports in the market, thereby allowing the weakest domestic firms to survive somewhat more easily by selling on the domestic market. ${ }^{1}$ However, this result comes at an important aggregate welfare cost, since the average efficiency of industry drops. This de-selection effect is also accompanied by an increase in the average price and mark-up as well as a reduction in (i) the number of products and varieties sold on the domestic market and (ii) the average scale of firms. In summary, protectionist moves trigger anti-competitive effects to the detriment of consumer welfare and prevent healthier firms from exploiting economies of scale, thereby weakening the whole productive apparatus of a country. At the same time, as a consequence of less accessible foreign markets, profits of domestic exporters are also depressed. ${ }^{2}$

\footnotetext{
1 This is shown by the increase in the area denoted "Home", which indicates an increase in firms that concentrate in home sales and a reduction in the area denoted "Exit", which indicates that the less competitive environment alllows more of the smaller and less productive firms to survive.

2 This is shown in the chart by a shift to the left of the parameter $\mathrm{c}_{\mathrm{s}}^{\text {th }}$ and a reduction of the area denoted as "Export".
} 
DETERMINANTS OF TRADE PERFORMANCE IN THE NEW MULTI-COUNTRY MODEL

Over the period 2000/08, average annual export growth rates varied significantly between the largest euro area countries, from 7.5\% (Germany) to $2.6 \%$ (Italy). As exports are normally considered to be a function of foreign demand and some measure of price competitiveness (normally relative export prices), this disparity in terms of export developments may indicate that there are significant cross-country differences in terms of the contribution of these determinants to explaining export performance. In this box, we use the export equations estimated for the largest euro area countries in the ECB's New Multi-Country Model (NMCM) in order to assess the main drivers of export performance

\section{Chart 30 Contribution analysis for the Multi-Country Model (exports)}

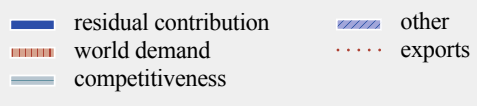

Germany

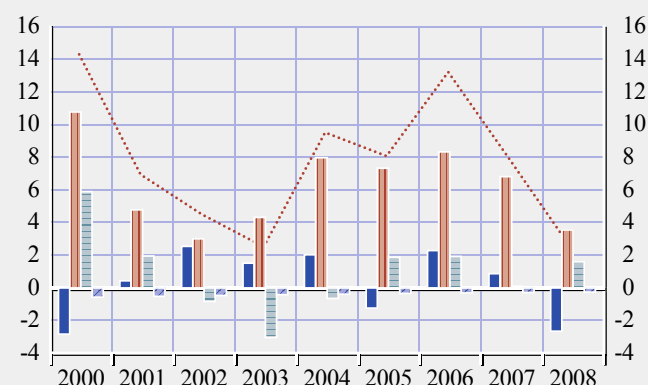

Italy

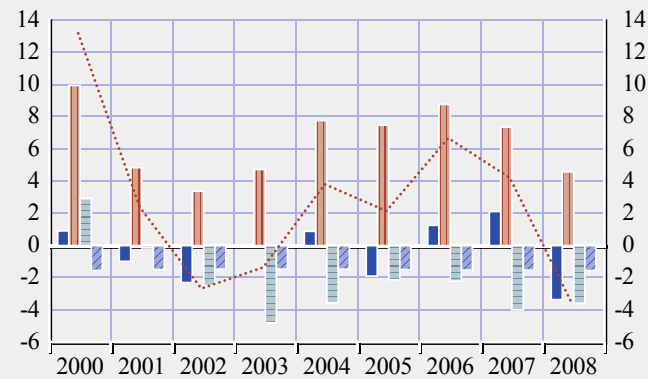

Netherlands

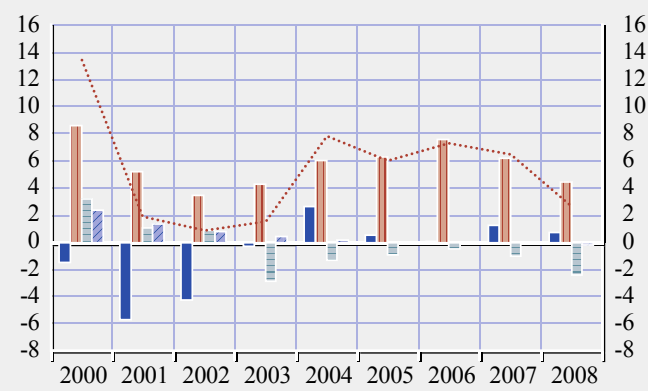

Source: ECB.

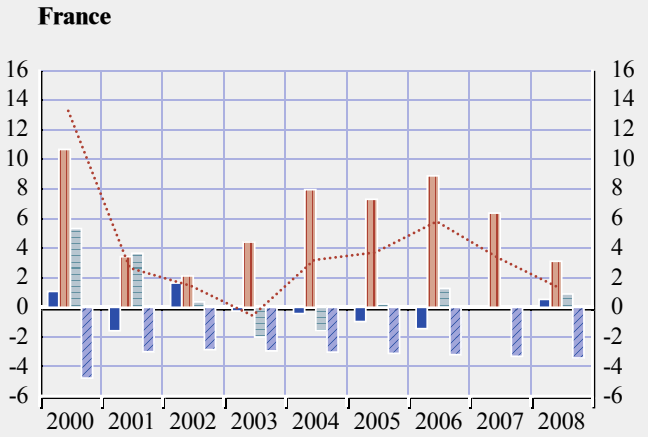

Spain

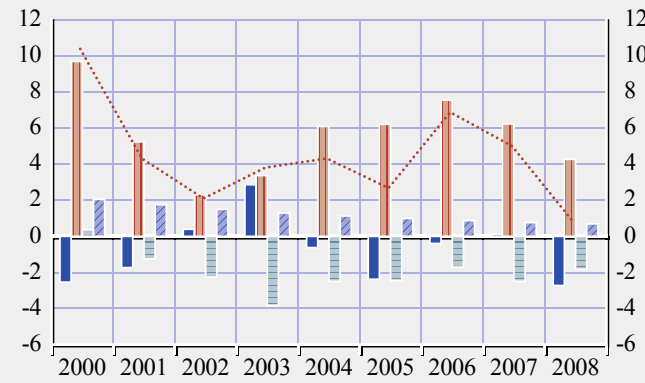


Chart 3 I Export volume equations: analysis of residuals

(as percentage of total exports; quarterly data)

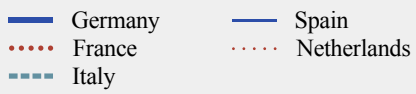

-"-" Italy

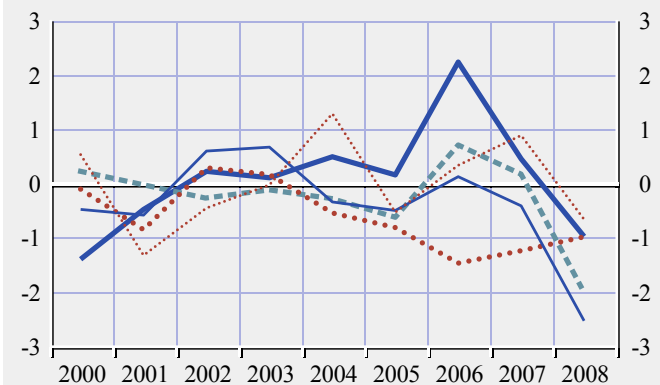

Source: ECB.

Notes: The equations refer to total (intra + extra euro area) export volumes of goods and services. A positive residual indicates that actual exports are above what is predicted by the equation.

during this period and its relative importance to these traditional determinants.

Overall, fluctuations in foreign demand seem to be the most important determinant of export performance for all five of the largest euro area countries during the period 2000/08 (see Chart 30). Moreover, the export growth of Italy, Spain and France, particularly after 2002, has been lower than the growth in foreign demand, suggesting a loss of export market share (by volume) for these countries. Price competitiveness seems to have played a particularly prominent role in explaining these losses in export market share in the case of Spain and Italy, especially since 2002, possibly providing an indication of relatively unfavourable domestic price and cost conditions in these two countries. Changes in unexplained

\begin{tabular}{|c|c|}
\hline Country & Price elasticity of exports \\
\hline Germany & 1.02 \\
\hline France & 1.06 \\
\hline Italy & 1.22 \\
\hline Spain & 1.31 \\
\hline Netherlands & 1.35 \\
\hline
\end{tabular}

factors, as captured by the equations' residuals, had a relatively smaller, but in some cases negative, impact on average annual export growth in 2000/08.

Indeed, the model residuals indicate that additional factors other than foreign demand developments and price competitiveness may have played a role in explaining the export growth of the five largest euro area countries (see Chart 31). These additional factors may typically include the technological and structural competitiveness of a country, as represented, for example, by $\mathrm{R} \& \mathrm{D}$ expenditure, patenting activity, human capital and overall business environment. Overall, the residuals show an overestimation of exports for France in contrast with an underestimation of exports for Germany during most of the period 2000/07, while there seems to be an overestimation of exports for all countries in 2008. This is in line with the analysis of standard indicators.

We also found that there are significant disparities between countries in terms of the relative price elasticity of export volumes. ${ }^{24}$ These vary from -1.02 (Germany) to -1.35 (Netherlands), as shown in Table 12. In particular, the export volumes of Germany and France appear to be less elastic to price changes compared to the export volumes of Italy, Spain and the Netherlands. This could partly be the result of different product mixes (including the quality hallmarks of products) and market segment targeting (e.g. niche or luxury goods markets) on the part of each country's exports. 


\section{REFERENCES}

Amador, J. and S. Cabral (2009), "Vertical specialisation across the world: a relative measure", North American Journal of Economics and Finance.

Anderton, R and T. Tewolde (2009), "Turmoil, global trade and the internationalisation of production", paper presented at the conference "The global financial crisis", University of Nottingham, China, 10-11 November 2010.

Auboin, M. (2009), "Restoring trade finance: what the G20 can do", published in "The collapse of global trade, murky protectionism, and the crisis: recommendations for the G20", ed. Richard Baldwin and Simon Evenett, London: Centre for Economic Policy Research.

Baldwin et al. (2009), “The great trade collapse: causes, consequences and prospects”, published in VoxEU.org, The Graduate Institute Geneva, November.

Bems, R., R. Johnson and K.-M. Yi (2010), "The Role of Vertical Linkages in the Propagation of the Global Downturn of 2008”, IMF, January.

Bricogne, J.-C., L. Fontagné, G. Gaulier, D. Taglioni, and V. Vicard (2009), "Firms and the global crisis: French exports in the turmoil”, Banque de France.

Bussière, M., A. Chudik and G. Sestieri (2009), "Modelling global trade flows: results from a GVAR model”, Working Paper Series 1087, European Central Bank.

Bussière, M., Pérez-Barreiro, E., Straub, R. and D. Taglioni (2010), "Protectionist responses to the crisis: global trends and implications”, ECB Occasional Paper No. 110, April.

Cheung, C. and S. Guichard (2009), “Understanding the world trade collapse”, OECD Working Paper No. 729.

Curran, L. and S. Zignago (2009), “The evolution of EU and its Member States' competitiveness in international trade”, report prepared by CEPII-CREM ATLASS consortium, DG Trade, European Commission.

De Benedictis, L. and M. Tamberi (2006), "Overall specialisation empirics: techniques and applications”, Open Economics, 15, 4, pp. 323-346.

Di Mauro, F. and K. Forster (2008), "Globalisation and the competitiveness of the euro area", ECB Occasional Paper No. 97, September.

Di Mauro, F., Dées, S. and M. Lombardi (2010), "Catching the flu from the United States: synchronisation and transmission mechanisms to the euro”, Palgrave Macmillan, New York.

ECB (2009), "Recent developments in euro area productivity”, Monthly Bulletin, Box 7, December, pp. $79-82$. 
ECB (2010), "Recent developments in global and euro area trade", Monthly Bulletin, August, pp. 93-107.

Eichengreen, B. and K.H. O'Rourke (2009), “A tale of two Depressions”, published in VoxEU.org.

European Commission (2010), "Quarterly Report on the euro area", Volume 9, № 2, 2010.

Freund, Caroline (2009), "The trade response to global downturns. Historical evidence", World Bank Working Paper No. 5015.

Hummels, D., J. Ishiib and K. Yi (2001), "The nature and growth of vertical specialisation in world trade", Journal of International Economics No. 54, pages 75-96.

Levchenko, A., L. Lewis and L. Tesar (2009), "The collapse of international trade during the 2008-2009 crisis: in search of the smoking gun", Research Seminar in International Economics, Discussion Paper No. 592, October.

Miroudot, S. and A. Ragoussis (2009), "Vertical trade, trade costs and FDI", OECD Trade Policy Working Paper No. 89.

Ottaviano, G., D. Taglioni and F. di Mauro (2009), "The euro and the competitiveness of European firms", CEPR, CES, MSH, vol. 24, pages 5-53.

Pula, G. and T. Peltonen (2009), "Has Emerging Asia decoupled? An analysis of production and trade linkages using the Asian international input-output table", ECB Working Paper No. 993, January. 


\section{EUROPEAN CENTRAL BANK}

OCCASIONAL PAPER SERIES SINCE 2009

100 "Survey data on household finance and consumption: research summary and policy use" by the Eurosystem Household Finance and Consumption Network, January 2009.

101 "Housing finance in the euro area" by a Task Force of the Monetary Policy Committee of the European System of Central Banks, March 2009.

102 "Domestic financial development in emerging economies: evidence and implications" by E. Dorrucci, A. Meyer-Cirkel and D. Santabárbara, April 2009.

103 "Transnational governance in global finance: the principles for stable capital flows and fair debt restructuring in emerging markets" by R. Ritter, April 2009.

104 "Fiscal policy challenges in oil-exporting countries - a review of key issues" by M. Sturm, F. Gurtner and J. Gonzalez Alegre, June 2009.

105 "Flow-of-funds analysis at the ECB - framework and applications" by L. Bê Duc and G. Le Breton, August 2009.

106 “Monetary policy strategy in a global environment" by P. Moutot and G. Vitale, August 2009.

107 "The collateral frameworks of the Eurosystem, the Federal Reserve System and the Bank of England and the financial market turmoil" by S. Cheun, I. von Köppen-Mertes and B.Weller, December 2009.

108 "Trade consistency in the context of the Eurosystem projection exercises - an overview" by K. Hubrich and T. Karlsson, March 2010.

109 "Euro area fiscal policies and the crisis" by editor Ad van Riet, April 2010.

110 "Protectionist responses to the crisis: global trends and implications" by M. Bussière, E. Pérez-Barreiro, R. Straub and D. Taglioni, April 2010.

111 "Main drivers of the ECB financial accounts and ECB financial strength over the first 11 years" by O. Vergote, W. Studener, I. Efthymiadis and N. Merriman, May 2010.

112 "Public wages in the euro area towards securing stability and competitiveness" by F. Holm-Hadulla, K. Kamath, A. Lamo, J. J. Pérez and L. Schuknecht, June 2010.

113 "Energy markets and the euro area macroeconomy" by a Task Force of the Monetary Policy Committee of the European System of Central Banks, June 2010.

114 "The impact of the global economic and financial crisis on central, eastern and south-eastern Europe: A stock-taking exercise" by S. Gardó and R. Martin, June 2010. 
115 "Financial stability challenges in EU candidate countries. Financial systems in the aftermath of the global financial crisis" by an IRC expert group of the ESCB, July 2010.

116 "Securities clearing and settlement in China - markets, infrastructures and policy-making", by P. Hess, July 2010.

117 "Extraordinary measures in extraordinary times - Public measures in support of the financial sector in the EU and the United States", by S. M. Stolz and M. Wedow, July 2010.

118 "The impact of the global financial turmoil and recession on Mediterranean countries' economies”, by M. Sturm and N. Sauter, August 2010.

119 "The global downturn and its impact on euro area exports and competitiveness", by F. di Mauro, K. Forster and A. Lima, October 2010 


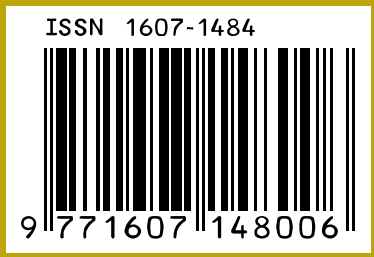

